\title{
Comparing effects of two collaboration scripts on learning activities for wiki-based environments
}

\author{
Sven Heimbuch, Lisa Ollesch \& Daniel Bodemer \\ University of Duisburg-Essen, Duisburg, Germany
}

\begin{abstract}
Knowledge construction assignments with wikis can be found in various educational settings. However, wiki environments are not inevitably suited to help learning and thus more guidance could be useful. In this study, we investigated the effects of two collaboration scripts with different aims during a two-week period of knowledge construction with wikis as a supplement to lectures about descriptive statistics. One script that is derived from Wikipedia's suggested workflow promoted a high frequency of individual article edits without further coordination, while the alternative script encouraged participants to discuss any planned changes upfront. Results showed that our proposed collaboration script encouraged students to take part in the whole script process, while in Wikipedia's script proposal only the first step of article editing was executed. These edits were generally of slightly lower quality. Learning success was not directly affected by the scripts, though the data suggests small effects in favour of our script proposal.
\end{abstract}

Keywords Wiki $*$ Collaboration scripts * Collaborative learning * Knowledge construction * Collaborative writing

\section{Introduction}

Wikis are web-based platforms that enable collaboration at virtually any point in time from any place between anyone who has access to a web-enabled device. They allow one or more persons to build up a corpus of knowledge in a set of interlinked web pages using a process of creating and editing pages (Chen, Jang, \& Chen, 2015; Franklin \& Harmelen, 2007; Richardson, 2010). Knowledge can be shared at any time with a whole community without any major restrictions. The focus of the current article is on the learning aspects rather than on information sharing. This is inspired by constructivist learning theory which assumes that individuals learn best when they have constructed knowledge on their own (Cole, 2009). Consequently, wiki environments are nowadays widely established as a valid educational technology in many contexts for collaborative knowledge construction, shared problem-solving, and other related learning tasks (Bartelsen \& Brauer, 2010; Notari, Reynolds, Chu, \& Honegger, 2016). Despite the common and wide use of wikis as computer-supported collaborative learning environments, their effective and meaningful use can be quite challenging for learners. Some of these challenges for collaboration with wikis can be an abundance of options and an unfamiliar structure (Zheng, Niiya, \& Warschauer, 2015). 
Instructional scaffolding as added guidance is often needed to exploit the full potential of collaborative learning, because unguided collaboration does not automatically result in learning benefits for users of such systems (Dillenbourg, 2002). One way of supporting individuals in computer-based collaborative learning environments is to give learners explicit instructions to organise their interactions (Bromme, Hesse, \& Spada, 2005). Wikis with their multiple layers such as article view, talk page, revision history - may not be utilised well without effective guidance. They are then used as environments for simpler collaborative article production without deeper elaboration (Biasutti, 2017). To analyse which type of explicit guidance is most beneficial for learners in wikis, we designed and conducted two experiments where students collaboratively constructed knowledge artefacts either in dyads (pre-study) or in larger groups (main study).

\section{Wiki-based collaborative knowledge construction and learning}

The internalisation and externalisation of knowledge from an individual's cognitive system into a wiki or vice versa contribute to the co-construction of socially shared artefacts (Cress \& Kimmerle, 2008). Social interaction in computer-supported collaborative learning (CSCL) environments can be considered as the essence of cognition (Dillenbourg, Järvelä, \& Fischer, 2009), because the creation or construction of knowledge can be regarded as a social product (Vygotsky, 1986). Furthermore, this view has been used to advocate the restructuring of education in the sense of shared problem-solving (Scardamalia \& Bereiter, 1994). Within these collaborative construction processes lay potentials for content-related controversies to occur that can trigger socio-cognitive conflicts. These kinds of conflicts arise from the clash of different perspectives or differences in prior knowledge of learners. Grounded in different opinions and contradictory or complementary knowledge, these controversies can be further used constructively to foster learning outcomes. The processing of such conflicts can trigger deliberation processes to reach a temporary consensus and so lead to the acquisition of new knowledge or broadening and restructuring of already existing knowledge. Moreover, when leading to more elaborate conflicts they can foster interest and support motivation (Isaacs \& Clark, 1987; Johnson \& Johnson, 1985; Johnson, Johnson, \& Smith, 2000).

In general, wikis provide great opportunities for collaborative learning where people learn best when they have designed their learning material themselves (Cole, 2009). As a basic wiki principle, there are no exclusion criteria for participation in any activity. In other words, every user has virtually equal rights in the social systems. Thus, there is the freedom to edit one's own created content, a third party's content or discuss uncertainties and give feedback to changes performed by others (Chen et al., 2015). The main goal is to freely share knowledge with the community at any time. Furthermore, wikis as web-based tools extensively document any changes made to the environment and thus give permanent, valuable insights into processes of collaborative knowledge construction (Biasutti \& EL-Deghaidy, 2012). Especially in higher education, they can be implemented in almost all kinds of degree course programmes to help collaborative learning of new definitions and concepts. Wikis have relatively intuitive basic functions to simplify collaborative learning and working, and their underlying structure and mechanisms can support learning processes and social interactions. Thereby, they offer many opportunities for collaborative knowledge construction. In the constructivist approach a disturbance of the cognitive balance was 
identified as a prerequisite for the construction of knowledge. This can lead to socio-cognitive conflicts that consequently can induce a reorganisation and restructuring of cognitions and ultimately manifests in learning growth for the individual (Bell, Grossen, \& Perret-Clermont, 1985). In the context of knowledge construction in CSCL environments such as wikis, an imbalance can be resolved by internalising information from the social system into one's own knowledge or by externalising knowledge from one's personal expertise. Another possibility for resolving an imbalance would be the restructuring of information in the wiki or restructuring one's individual schemata. These processes match assimilation and accommodation processes to restore an equilibrium that was disturbed by a socio-cognitive conflict (Cress \& Kimmerle, 2008; Piaget, 1977).

\section{Relevance of guidance for learners}

A key part of meaningful interactions between collaborating learners is that the interaction has a clearly specified learning goal or task. Thus, it might be required to predefine and provide certain rules or guidelines for specific tasks, such as creating or updating wiki articles and their corresponding discussion pages (Bromme et al., 2005). This can be rooted in the observation that persons working collaboratively on the same document often implicitly take over different roles and activities, and make use of certain strategies that are not necessarily best suited for effective collaboration (Posner \& Baecker, 1992). Especially in high-level collaboration, a certain level of supplemental guidance is necessary to reach the full potential of collaborative learning (Weinberger, Stegmann, Fischer, \& Mandl, 2007). Such guidance can be provided with the implementation of collaboration scripts where the activities of writers and editors within a social system are coordinated and optimised in a set of instructions. These can be used to specify the group formation, modes of interaction and task management between collaboration partners (Dillenbourg, 2002; Kollar, Fischer, \& Hesse, 2006). There is a trade-off between effective structuring and over-scripting that needs to be considered when choosing the complexity of a script. Recent research has proposed that additional scripts should be applied to wikis to improve the overall quality of knowledge artefacts and coordination processes of students (Wichmann \& Rummel, 2013). In this research on wiki-based writing, different collaboration scripts have been shown to be effective for students. Positive effects have been found for scripts with a special focus on article editing and revising that ultimately led to more coherent articles and fewer inaccurate articles. Furthermore, it has also been shown that a certain level of coercion in the implemented collaboration script can be helpful (Papadopoulos, Demetriadis, \& Weinberger, 2013).

To make use of the potentials that participatory learning environments provide to learners, individual differences should be considered when designing learning scenarios that are aimed at collaboration. Very explicit instructions to externalise mental representations of learned content and actively participate in the revision process can be beneficial. This is especially true for novice learners who are less familiar with the domain and thus need more guidance than more experienced learners (Kirschner, Sweller, \& Clark, 2006). Large wikis such as Wikipedia have created suggestions for how to create and revise articles. One specific instructional set has emerged that can be referred to as a script for collaborative writing in wikis: Wikipedia's so-called Be Bold, Revert, Discuss (BRD) cycle. It promotes a high frequency of individual article edits without the 
need of immediate coordination when changes are about to be made ("Wikipedia:BRD," 2017). The first step in this script encourages content creators to be bold and perform an edit to an existing article or create an entirely new article, if one feels the desire to do so. The second step encompasses guidelines on how to continue if an edit gets reverted. The last step of discussing edits suggests accepting at least three revisions before a discussion becomes required. These steps are not necessarily designed to be followed in an invariant order, although flow chart representations as used in Wikipedia and the like might suggest a specific order of events.

In contrast to the BRD proposal, we think setting a stronger focus on the discussion aspect of wiki-based knowledge construction is important and has much potential for learning. Thus, we propose an alternative approach with a different script approach that is more in line with current research findings of the learning sciences. It is inspired by wiki-based learning experiments that targeted the improvement of writing and more effective coordination (Papadopoulos et al., 2013; Wichmann \& Rummel, 2013). We aimed this alternative script at promoting participants to discuss any planned article edits and revisions upfront before any change to a document will be performed (Discuss, Deliberate, Revise = DDR). The first step in this script suggests that editors first take planned article edits to the corresponding discussion space. In the second step, a deliberation process is started where the community seeks to find a consensus about the proposed wiki edits. And finally, in the last step after having reached a temporary consensus the article revision can be performed. These two different script approaches (cf. Figure 1) were designed with different goals in mind. In the current paper, we investigate the potential for learning of each script in laboratory (pre-study) and field settings (main study).
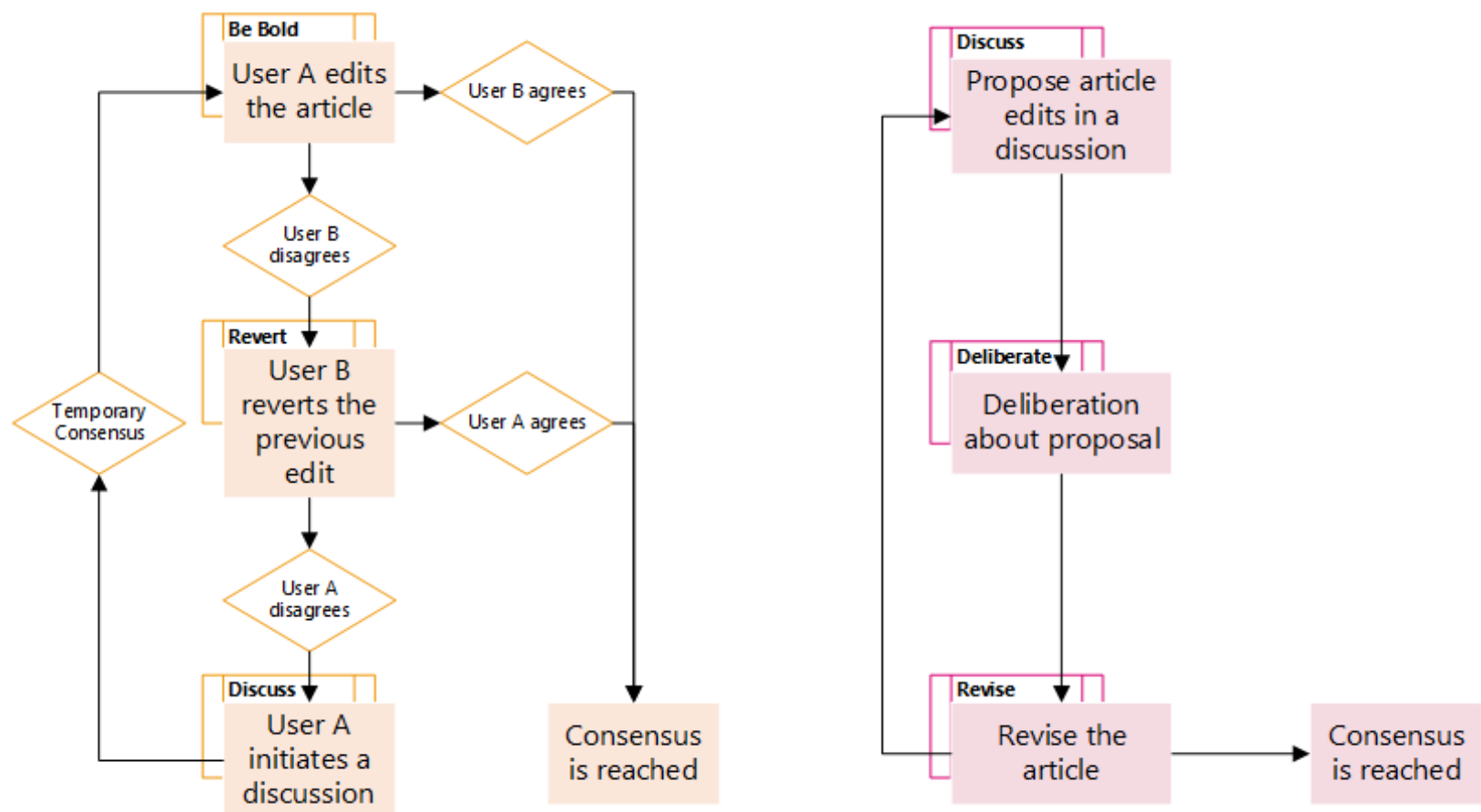

Figure 1. Representations of the Be Bold, Revert, Discuss (left) and Discuss, Deliberate, Revise (right) collaboration scripts' core stages as a flow chart. 


\section{Individual influences in the learning process}

Besides individual levels of experience with a subject matter, it has been discussed that individual personality differences should be considered in supporting and analysing learning processes (e.g., Cress \& Kimmerle, 2017; Heimbuch \& Bodemer, 2015). This paper focuses on three constructs that can be relevant for collaborative learning processes and outcomes.

(1) The effort a learner is willing to invest in searching for solutions to a problem during a learning process has been shown to be influenced by the individual's Need for Cognitive Closure (NCC). Various empirical results and discussions of the construct illustrate that the NCC can be regarded as a relevant key construct in knowledge creation processes (Webster \& Kruglanski, 1994). It is a motivational continuum between a strong need to get a concrete answer in an ambiguous situation and the avoidance of such ambiguity. Within the construct a distinction is made between two tendencies: urgency and permanence. In this context, the urgency tendency means that individuals feel the urge to achieve cognitive closure as quickly as possible. The permanence tendency is understood as the desire to maintain cognitive closure for as long as possible (Kruglanski \& Webster, 1996). Individuals with a high NCC want a definite answer in a judgement situation and show high urgency and permanence tendencies (Schlink, 2009). They are more likely to experience impatience to quickly reach a state of cognitive closure and once a satisfactory state is reached, they to try to keep this level of achieved cognitive closure. There has been considerable research into the influence of situational variables on the NCC, such as time pressure (De Grada, Kruglanski, Mannetti, \& Pierro, 1999). However, it has already been shown that the NCC also indicates stable interindividual differences (Webster \& Kruglanski, 1994). Thus, a high dispositional NCC is closely related to a reduction in the internal hypotheses building process (Kruglanski \& Mayseless, 1987; Kruglanski \& Webster, 1996). Furthermore, people with high levels of NCC tend to base their decisions on simple heuristics (Dreu, Koole, \& Oldersma, 1999), whereas low NCC individuals enjoy to consult more information in situations of uncertainty (Schlink, 2009). In wiki-based learning, we expect that low NCC individuals are more likely to search purposefully for more in-depth information about a topic in an ambiguous situation like a controversial discussion. Although this construct is closely tied to inter-individual differences in learning and knowledge construction, it has yet rarely been covered in studies of technologyenhanced or computer-supported collaborative learning. Therefore, we address this gap in an experimental pre-study and a follow-up main study on learning and knowledge construction in wiki-based environments that are supplemented by two distinct kinds of collaboration scripts.

(2) In past and recent research on learning and knowledge construction, motivational differences have been discussed as an interesting latent construct for different learning scenarios, including both face-to-face classroom learning and computer-supported collaborative learning (Leppink, 2010; Leppink, Gog, Paas, \& Sweller, 2015). Learner actions that are motivated intrinsically can be a key to effective learning (Deci \& Ryan, 1985; Nakamura \& Csikszentmihalyi, 2014). Intrinsically motivated persons frequently feel the need to be socially connected to a community while maintaining high levels of personal autonomy and self-determination (Deci \& Ryan, 1992). This does not necessarily mean that intrinsic motivation can only be experienced in isolation, it can also be triggered by external sources in a formal or informal learning setting (Wilde et al., 2009). In principle, wikis offer their users open spaces and enough leeway on self-chosen 
thematic foci for intrinsically motivated learning. This in turn requires consistent willingness to show initiative which can be initially triggered by the environment itself (Dillenbourg et al., 2009). The opportunities to introduce one's prior knowledge and experiences into such a social system can increase an individual learner's motivation. Highly intrinsically motivated learners can be central actors in meaningful socio-cognitive discourses that can be beneficial for more elaborated learning (Rienties, Tempelaar, Van den Bossche, Gijselaers, \& Segers, 2009). Motivation in group learning activities is an essential component that is still not covered well enough in research, whether analysing individual or collaborative learning processes (Järvelä, Volet, \& Hana Järvenoja, 2010). Therefore, in wiki-based learning where students have differing degrees of freedom depending on the task, motivational states can be a relevant influencing factor for successful learning.

(3) Closely related to motivational states is the concept of metacognition, which can be defined as reflective and regulative knowledge about the own knowledge (Efklides, 2008; Flavell, 1979; Kuhn, 2000). Metacognition is often regarded as an individual and conscious process that can also unconsciously operate on a social level during co-regulation in collaborative settings (Efklides, 2008). It is connected to first-order cognitions by monitoring and control functions. These metacognitive functions are required for self-regulated learning processes, where self-motivation and the choice of appropriate learning strategies become relevant (Zimmerman, 2002). Essentially, two distinct levels of metacognitive processes are discussed: the object- and the meta-level. These two levels interact and exchange information with each other via monitoring and control functions. The meta-level is informed by monitoring processes with information about cognitive activities on the object-level. Control functions ensure that meta-level orders reach the object-level (Veenman, Van Hout-Wolters, \& Afflerbach, 2006). Besides these levels, metacognition includes three involved facets: metacognitive knowledge, metacognitive experiences and metacognitive skills. Metacognitive knowledge encompasses explanatory knowledge about tasks, strategies and goals of others or oneself (Flavell, 1974). Metacognitive experiences include everything that a person knows and feels during the execution of a task (Efklides, 2006). Experience makes the state of cognitions conscious and triggers control processes that serve the goals of self-regulation. Both metacognitive knowledge and metacognitive experiences are associated with monitoring functions. In contrast, metacognitive skills stand for knowledge of practical value that is triggered by the other two facets of metacognition. The use of metacognitive strategies can be crucial for successful learning, although their effectiveness is not absolutely certain (Berthold, Nückles, \& Renkl, 2007). Planning, monitoring and evaluating learning processes is often regarded as timeconsuming and painstaking which is why, despite the availability of metacognitive strategies, existent skills are not always effectively used (Neuenhaus, Nora, 2011). In wikis where by default only loose (at best) guidance measures for any of the processes are implemented, students with less distinct metacognitive strategies might experience collaboration with wikis as unpleasant and could be reluctant to take part.

\section{General research questions and hypotheses}

In a first small-scale experimental laboratory pre-study, we explored two different scripts in a wiki-based learning environment - (1) Wikipedia's proposal, Be Bold, Revert, Discuss (BRD), in 
contrast to (2) our alternative proposal, Discuss, Deliberate, Revise (DDR). The former script is directed at externalising as much knowledge from an individual into the wiki as possible. The latter script aims at fostering deeper elaboration processes by encouraging discussions prior to the externalisation of knowledge into the wiki. Our results show that it is beneficial for mentally integrating different perspectives about a topic. To further support and extend these findings we have conducted a follow-up field experiment as main study. We expected that collaboratively working on a wiki in an educational context is most beneficial for students when they are first guided into discussions rather than encouraged to edit individually without further coordination. In both studies, we were interested in potential direct effects of the collaboration scripts. Quality markers in research on quantitative content analysis have been the number of contributions to the discussion (Stvilia et al., 2005; Viegas, Wattenberg, Kriss, \& Ham, 2007), the number of edits (Arazy, Morgan, \& Patterson, 2006; Lih, 2004; Wilkinson \& Huberman, 2007), the article length (Blumenstock, 2008) and the number of formal errors (Wichmann \& Rummel, 2013). We also collected data on influencing variables that can be related to learning and knowledge construction processes to gain deeper insights about potential indirect conditional effects (cf. Figure 2). Based on the theoretic findings, we therefore come to the following research questions and hypotheses:

$R Q 1$ : Does a DDR script have a greater positive impact on learning and the wiki article quality than Wikipedia's proposed BRD script does?

H1: We expect that a DDR script proposal encourages learners to engage in more discussions about a subject matter and thus leading to higher knowledge gains and contributions of higher quality.

H1.1: A DDR script leads to higher test scores and knowledge gains.

H1.2: A DDR script leads to less error-prone and more concise articles.

H1.3: A DDR script leads to more discussions and less article edits.

Whereas the first research question and hypothesis are confirmatory, due to a relatively large body of research about collaboration scripts and their effects, the second research question is more exploratory. We are interested in exploring the potential moderating effects of individual differences on outcome and process variables. The body of research in computer-supported collaborative learning is rather small regarding the Need for Cognitive Closure, metacognitive strategies, and intrinsic motivation.

$R Q 2$ : To what extent do the individual cognitive variables influence the effects on knowledge construction and the frequency of wiki activities in the talk page discussion forums?

H2: The script effects on the wiki contributions and learning outcome are affected by the individual levels of Need for Cognitive Closure, metacognitive strategies, and intrinsic motivation.

H2.1: A DDR script is expected to be more beneficial for knowledge gains for persons with (1) a low NCC, (2) less pronounced metacognitive strategies, and (3) high intrinsic motivation. 
H2.2: A DDR script is expected to maximise wiki contributions for persons with (1) a high NCC, (2) less pronounced metacognitive strategies, and (3) high intrinsic motivation.

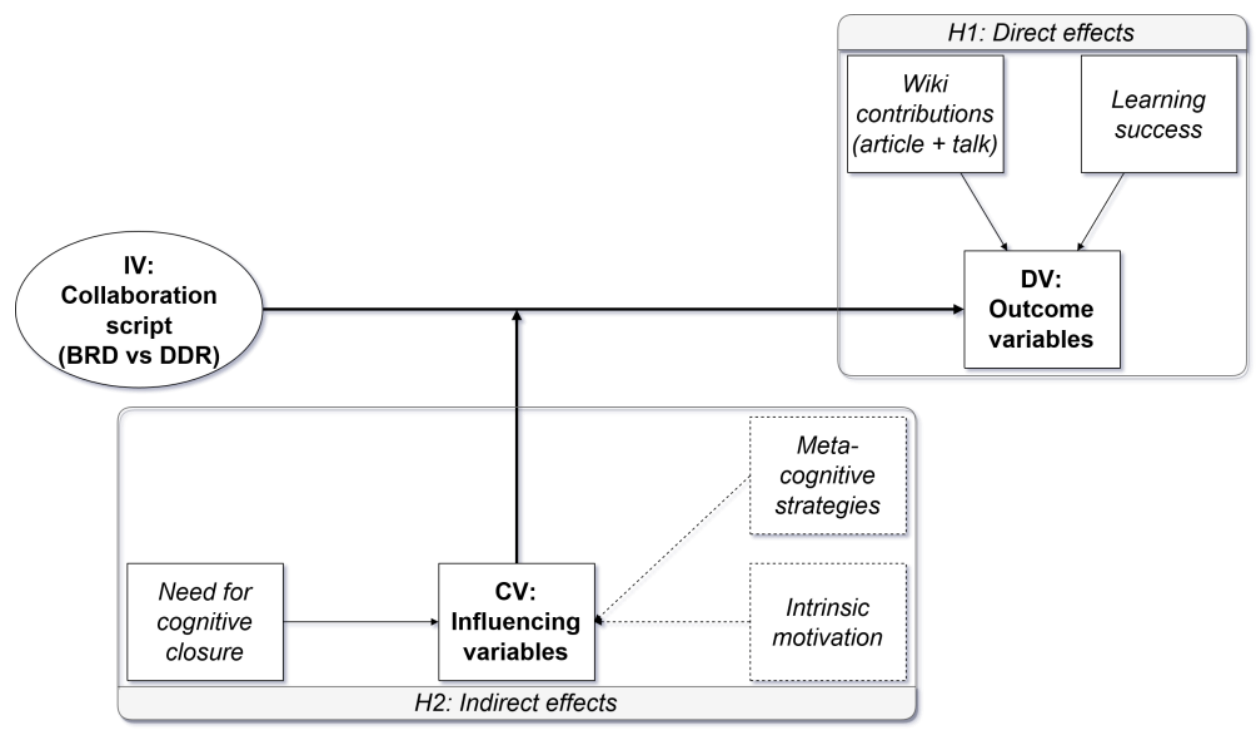

Figure 2. Hypothesis model: a) representing the anticipated direct relationship between the independent variable (collaboration script) and the main dependent variables; b) the indirect effects of the influencing variables on this relationship. Meta-cognitive strategies, and intrinsic motivation (dashed boxes) were only investigated in the main study, the Need for Cognitive Closure (solid box) was assessed both in the pre-study and the main study.

\section{Methodological similarities of the experimental studies}

Prior to working on any collaborative wiki writing or discussion tasks, students were introduced to the respective operational sequences of the BRD and DDR scripts. Therefore, we integrated detailed BRD and DDR collaboration script texts with mandatory tutorials on the first wiki login and presented additional script representations to emphasize the main stages as constant reminders, in either a wiki-like learning environment mimicked with Etherpad instances (pre-study) or a Wikipedia-inspired setup that we build with DokuWiki (main study). Students were randomly assigned to one of the two collaboration script groups in both experiments and worked either in dyads in the pre-study or in two large groups in the main study. The primary task in both experiments was to collaboratively edit already existing wiki contents that had either been generated by the experimenters (pre-study) or by students themselves in an earlier unrelated study (main study). Despite the differences in settings and setups, participants in both experiments were asked to fill out the 16-NCCS (Schlink \& Walther, 2007), a short questionnaire on the individual Need for Cognitive Closure. The questionnaire consists of 16 statements to be rated on a six-point scale about how one deals with ambiguity, each item ranging from "fully disagree" (1) to "fully agree" (6). Additionally, in the main study further measurements of influencing variables were conducted that were not previously addressed in the pre-study, namely metacognitive strategies and intrinsic motivation. In both studies we rewarded participants with a certificate of attendance needed for course credit. 


\section{Use and reporting of statistical analyses}

Effects represented by proportions of variance $\left(\eta^{2}, R^{2}\right)$ are reported with $90 \%$ confidence intervals, and for effect sizes based on standardised means $(d, r) 95 \%$ confidence intervals are used (Steiger, 2004). Due to the small- to medium-sized samples there was an increased likelihood of not meeting the assumption of either normality or equal variances; therefore, we applied the more robust Welch's $t$-Tests for our main statistical analyses instead of Student's $t$-Test (Ruxton, 2006). When more than one assumption of parametric tests was violated (e.g. normality and homoscedasticity of residuals) and/or sample sizes were very small as it was the case for the prestudy, we used non-parametric statistical tests for the analyses. Although the data for both experiments is in principle nested, we decided against the reporting of hierarchal linear mixed models (also known as multilevel models) and used individuals as unit of analysis because of several reasons: (1) the sample sizes were small to medium and for multilevel models to produce interpretable outcomes, a much larger $N$ for the lowest level would be required (Cress \& Kimmerle, 2008; Hox, Moerbeek, \& Schoot, 2010; Huang, 2016; Snijders \& Bosker, 2011); (2) both experiments had only two experimental groups as highest level grouping factor and for $j<10$ multilevel models do not add any statistical benefits and therefore OLS techniques such as ANCOVA and related parametric tests are most suitable and produce highly similar results (Hox et al., 2010; Snijders \& Bosker, 2011); (3) the intraclass correlations as check for nonindependence of the data were close to zero (Kenny, 1995), e.g., for the learning outcomes in the pre-study: ICC $=.02,95 \%$ CI $[-.06, .99], F(13,14)=0.02, p>.999$. For other dependent outcome and processrelated variables, the intraclass correlation was even closer to zero; (4) for the main study a likelihood ratio test comparing the single level model to multilevel model resulted extremely close to zero, $L R=-5.68 \mathrm{e}-14$. Even under most optimistic circumstances, the multilevel model approaches with random slopes explain at best less than $1 \%$ added variance of the data; (5) thus, non-parametric and robust tests (e.g., Welch's $t$-Test, Bootstrapping CIs), as used for the analyses of both studies, are appropriate.

\section{Pre-study - Method}

\section{Design and participants}

We conducted the pre-study as a two-group between-subjects experiment with participants working in groups of two. At the start of the laboratory experiment (t1), the sample consisted of $N$ $=28$ university students (14 females, 14 males) with a mean age of $M=23.29$ ( $S D=5.72)$. Participants rated their topic-specific interest as medium to high and their self-assessed prior knowledge ranged between low and moderate on six-point scales ranging from "not interesting at all" / "no prior knowledge" (0) to "very interesting" / "high prior knowledge" (5). Between groups, there were negligibly small to virtually no differences in the general or concrete topic-specific interest and even smaller differences close to zero in prior knowledge (cf. Table 1). Two weeks after the lab study (t2), participants were asked to take part in an online post-test about the subject matter. $N=22$ students ( 12 females, 10 males) completed this post-test. 
Table 1. Analyses of group difference in interest and prior knowledge.

\begin{tabular}{llllll}
\hline & Topic & $U$ & $p$ & $r$ & $95 \%$ CI \\
\hline Interest & Pirates in general & 62.00 & .104 & -.32 & {$[-.62, .06]$} \\
& William Kidd & 73.00 & .265 & -.23 & {$[-.56, .15]$} \\
\hline Prior knowledge & Pirates in general & 72.00 & .246 & -.24 & {$[-.46, .28]$} \\
& William Kidd & 92.50 & .769 & -.11 & {$[-.46, .28]$} \\
\hline
\end{tabular}

\section{Procedure and variables}

The study's main task in both groups was to edit a wiki article about the alleged pirate Captain William Kidd with the help of contradictory supplementary materials. Each participant received individually either evidence for (A) supporting the theses that William Kidd was a pirate and the conviction was justified or with (B) evidence that contradicts the theses. In the collaboration phase a basic article about William Kidd was preloaded into the learning environment. This article was structured in a way to mimic a standard Wikipedia article and had a total length of 810 words. The main independent variable was the varying collaboration script. Participants were randomly assigned to either the collaborative editing workflow proposed by Wikipedia (BRD) or to the script we designed with a stronger focus on discussion and deliberation (DDR). Detailed script instructions were given as texts and were further accompanied by graphical representations of the most relevant phases of the scripts that were permanently visible in the learning environment (cf. Figure 3).
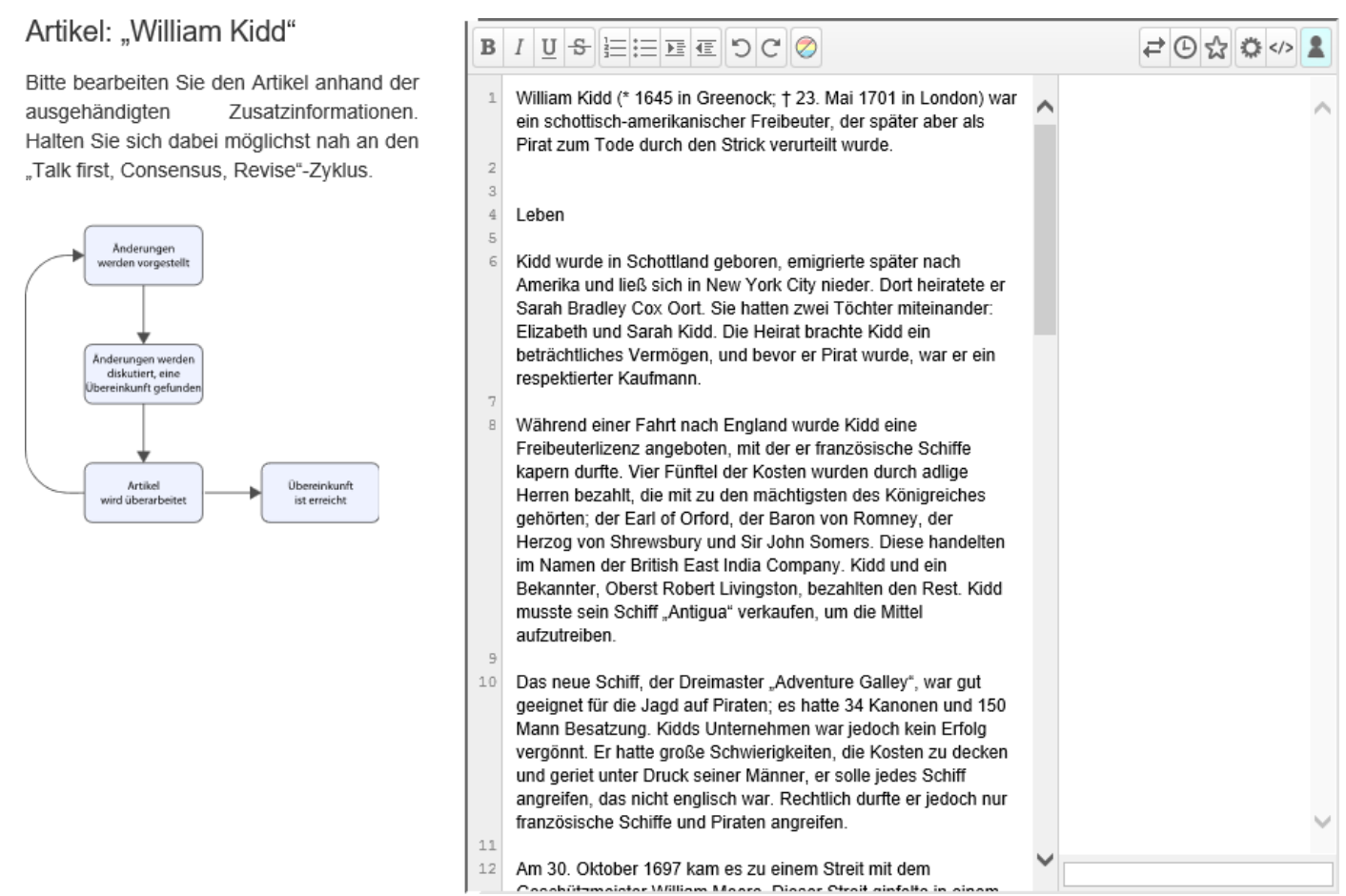

Figure 3. Wiki-like learning environment realised with Etherpad showing a permanent flow chart of the script's main stages as a reminder (pre-study). 
In addition to socio-demographic variables (e.g. gender and age), topic-specific interest and prior knowledge about the study's topic were assessed. To measure the impact either collaboration script had on the knowledge construction processes and learning outcomes, we recorded wiki contribution metrics and deployed two knowledge tests. Contributions to the wiki were analysed in terms of article length, discussion length and the number of newly added evidence that was incorporated into the article. Measures of article and discussion length functioned as quality indicators, but also as manipulation checks to infer if participants collaborated following the respective script. Between the collaborative writing task and the first assessment of learning outcomes, participants were asked to fill out the 16-NCCS. We measured the learning outcomes at two points in time, directly after the collaboration phase at the end of the experiment (t1) and two weeks later with an invitation-only online questionnaire (t2). The two knowledge tests to measure the learning outcomes each included ten multiple choice questions with four alternative answers and two open-ended questions. In each of the multiple-choice tests, a total score of 17 correct answers could be achieved. In the open-ended questions participants were asked if they think that (1) Captain William Kidd was a real pirate and (2) if his conviction was justified. These questions were used to assess whether a participant gave only arguments presented in their own supplementary material (A or B), or if they gave more differentiated statements by integrating the evidence from their partner's material (A and B). Figure 4 shows the overall study procedure and highlights when the independent variable was manipulated, and dependent variables were measured.

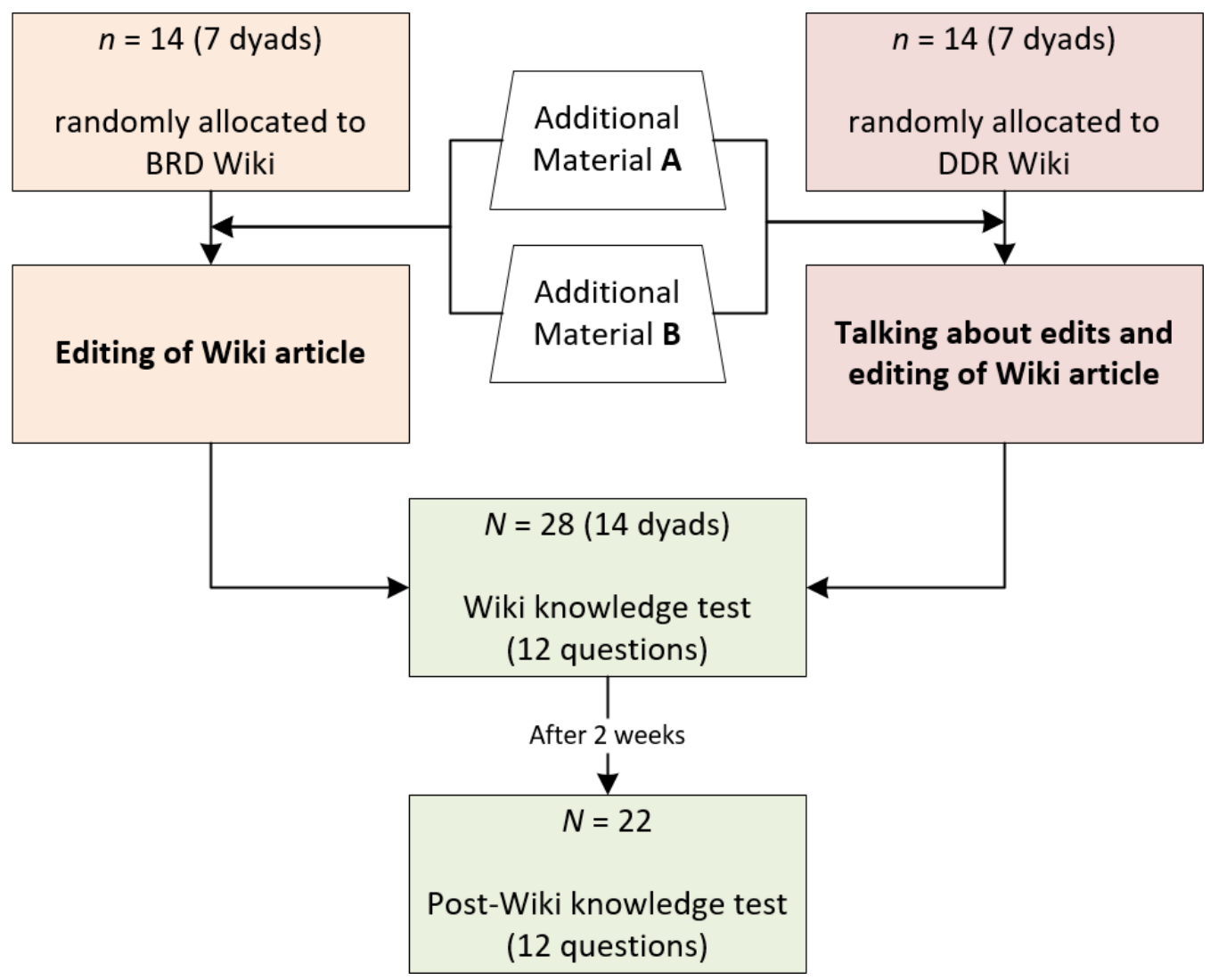

Figure 4. Overall study procedure of the pre-study. 


\section{Pre-study - Results and Discussion}

\section{Direct group comparisons}

Regarding the participants' contributions, we analysed the article lengths at the end of the collaboration, the integration of new evidence from the supplementary materials as well as individual chat $\operatorname{logs}$ (cf. Table 2). The chat log was also meant to serve as a manipulation check to infer from the intensity of the discussions if dyads have followed their respective collaboration script. One dyad was excluded from the chat log analyses because of inappropriate discussion behaviour.

Table 2. Descriptive statistics and analyses of article revision and discussion metrics.

\begin{tabular}{lcrrrrrr}
\hline & & \multicolumn{1}{c}{$M$} & \multicolumn{1}{c}{ SD } & $U$ & $p$ & $r$ & $95 \%$ CI \\
\hline Article length & BRD & 1202.57 & 99.43 & & & & \\
(words) & DDR & 1218.43 & 153.69 & 96.00 & .945 & .02 & {$[-.39, .43]$} \\
\hline New evidence & BRD & 9.43 & 2.15 & & & & \\
(count) & DDR & 8.43 & 2.82 & 120.00 & .318 & .22 & {$[-.20, .58]$} \\
\hline Chat length & BRD & 133.64 & 94.01 & & & & \\
(words) & DDR & 283.08 & 186.35 & 58.00 & .035 & .41 & {$[-.07, .66]$} \\
\hline
\end{tabular}

Learning outcomes. The participants' knowledge was assessed the first time after the experiment's collaborative writing phase (t1). To measure potential differences in the consolidation of knowledge, a second measurement of the learning outcomes was conducted two weeks later (t2). Overall, participants in the BRD group scored two points lower compared to the DDR group (cf. Table 3). In direct comparison, learners working on an article according to the DDR script achieved moderately higher test scores right after the collaboration and this difference in favour of the DDR script remained relatively stable after two weeks, although due to the small sample size the estimates lack statistical precision.

Table 3. Descriptive statistics and analyses of knowledge test scores.

\begin{tabular}{llllllll}
\hline & & $M$ & $S D$ & $U$ & $p$ & $r$ & $95 \%$ CI \\
\hline Overall score & BRD & 23.67 & 2.06 & & & & \\
& DDR & 25.54 & 3.89 & 32.50 & .043 & .44 & {$[-.06, .72]$} \\
\hline Test score t1 & BRD & 12.33 & 1.12 & & & & \\
& DDR & 13.46 & 2.96 & 66.50 & .074 & .32 & {$[-.03, .60]$} \\
\hline Test score t2 & BRD & 11.33 & 1.00 & & & & \\
& DDR & 12.08 & 1.61 & 40.50 & .111 & .31 & {$[-.10, .63]$} \\
\hline
\end{tabular}


Perspective integration. We categorised the two open-ended questions whether a participant answered only with one's own supplementary learning material (A or B) or by additionally integrating evidence or arguments from their learning partner's supplementary material (A and B). For the first question regarding Captain William Kidd's alleged pirate status, BRD and DDR script groups differed largely in their answering behaviour at $\mathrm{t} 1, \chi^{2}(1, N=28)=7.34, p=.007$ and remained relatively stable, although with less precise estimates due to an even smaller sample, at $\mathrm{t} 2, \chi^{2}(1, N=22)=2.20, p=.138$. The odds of incorporating evidence from the partner's learning material into one's own answer was 10.80 times higher at $\mathrm{t} 1$ and 4.08 times higher at $\mathrm{t} 2$ if students collaborated with the DDR script (cf. Figure 5).
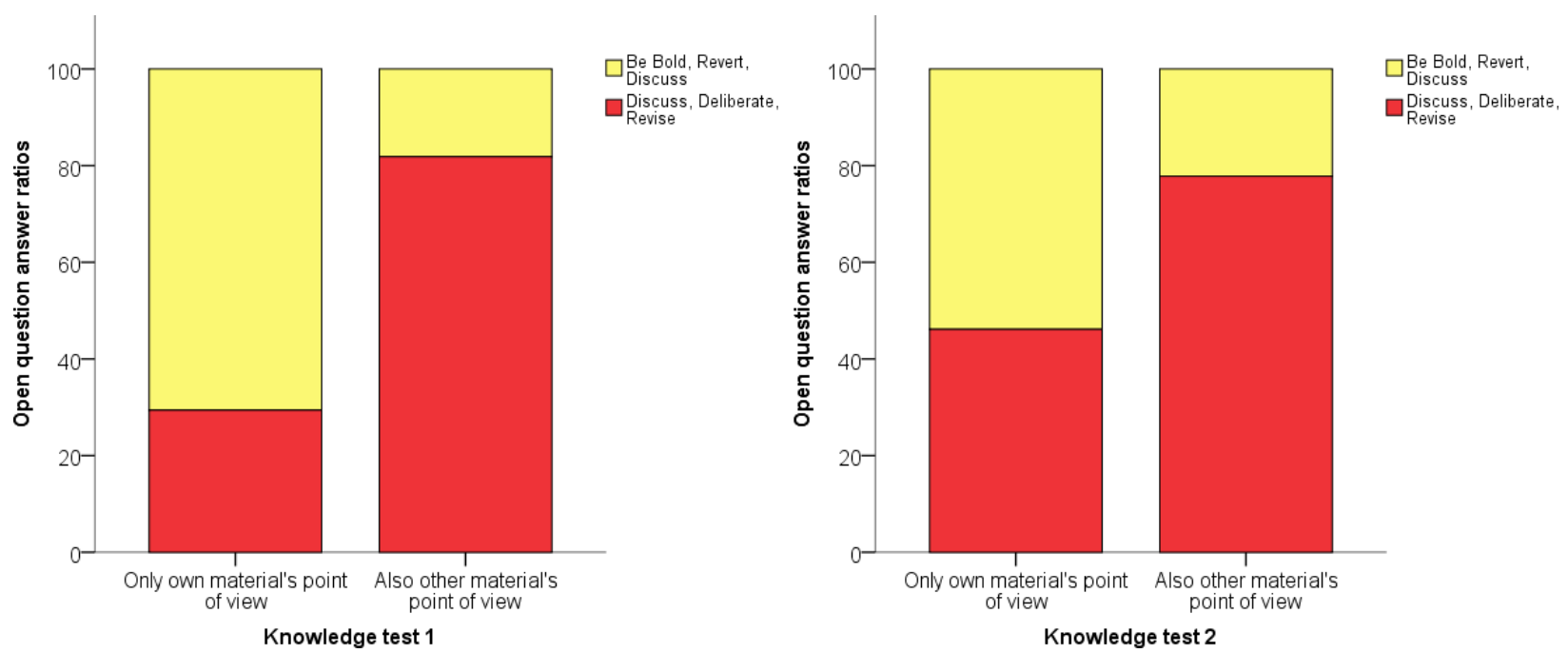

Figure 5. Incorporation ratios of arguments as present in one's own learning material and the learning partner's material at $\mathrm{t} 1$ (left) vs $\mathrm{t} 2$ (right).

Regarding the second open-ended question about William Kidd's conviction, there were absolutely no relevant differences in the answering behaviour at $\mathrm{t} 1$ and $\mathrm{t} 2, \chi^{2}(1, N=27)=0.07, p$ $=.785$ and $\chi^{2}(1, N=20)=0.59, p=.444$, respectively. The odds of incorporating evidence from the partner's learning material into one's own answer was 0.80 times higher at $\mathrm{t} 1$ and 2.14 times higher at $\mathrm{t} 2$ if they collaborated using a DDR script.

\section{Need for Cognitive Closure (NCC)}

As a final exploration, we used Spearman's rank-correlations (cf. Table 4) and scatterplots with regression slopes (cf. Figure 6) to investigate the potential relationships between the NCC, the wiki metrics and the learning outcome. The results show different trends for both groups, although they should be taken with care due to the small sample size and low precision of estimates. 
Table 4. Correlations of the NCC with the main dependent variables.

\begin{tabular}{llrrr}
\hline & & \multicolumn{1}{l}{$r_{s}$} & \multicolumn{1}{l}{$95 \%$ CI } \\
\hline Article length & BRD & -.34 & .119 & {$[-.74, .24]$} \\
(words) & DDR & .36 & .107 & {$[-.22, .75]$} \\
\hline New evidence & BRD & -.31 & .139 & {$[-.72, .26]$} \\
(count) & DDR & .29 & .155 & {$[-.28, .71]$} \\
\hline Chat length & BRD & .25 & .191 & {$[-.32, .69]$} \\
(words) & DDR & .04 & .448 & {$[-.50, .56]$} \\
\hline Knowledge test & BRD & .26 & .250 & {$[-.49, .79]$} \\
(scores) & DDR & -.14 & .326 & {$[-.64, .45]$} \\
\hline
\end{tabular}
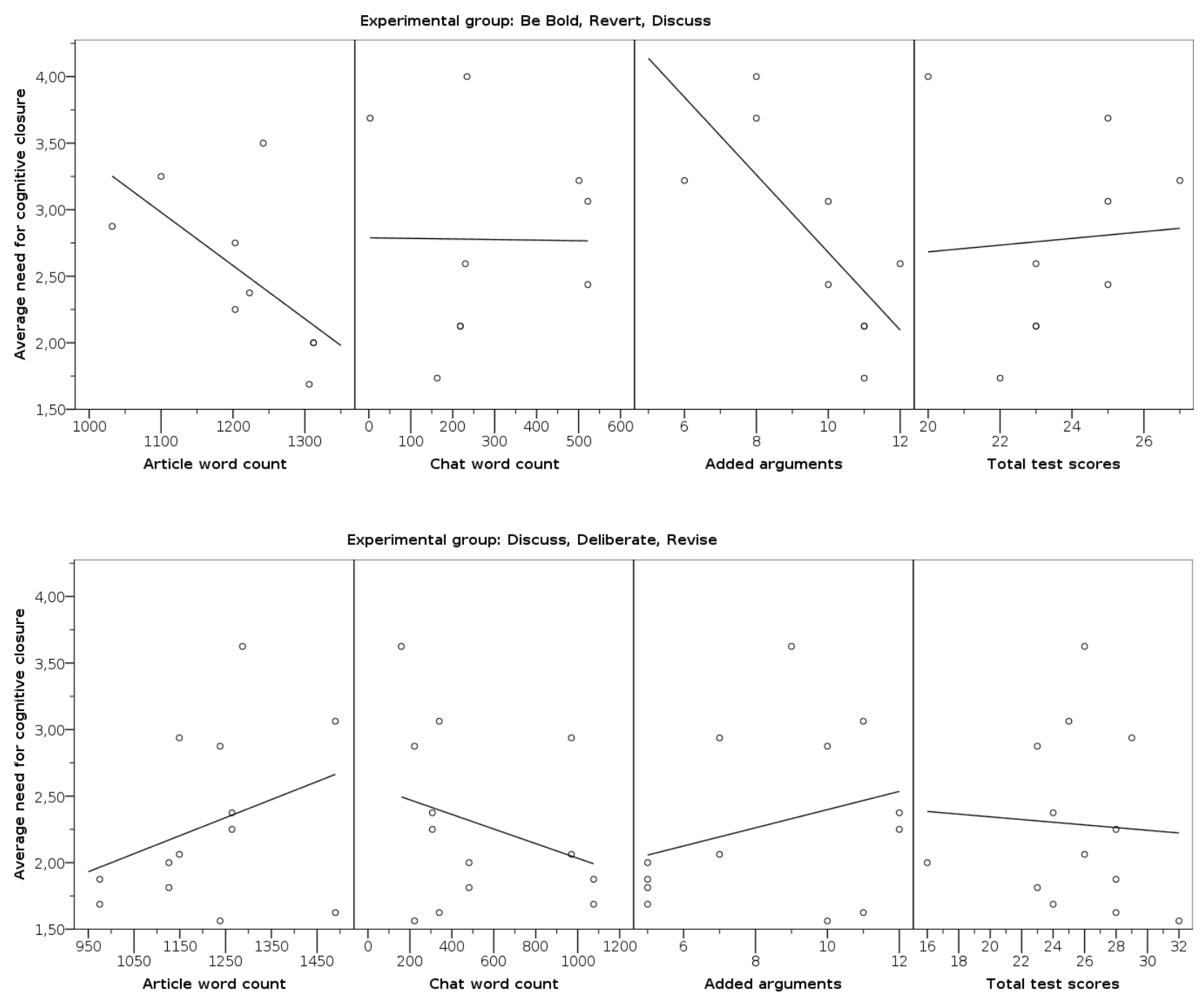

Figure 6. Correlation matrices of the NCC scatterplots for the Be Bold, Revert, Discuss script (top panel) and the Discuss, Deliberate, Revise script (bottom panel). 
Summary of the pre-study's key findings

The central result of this experimental pre-study is that when dyads followed their respective collaboration script, the resulting outcomes and processes differed quite substantially. Students in the DDR script group were encouraged to do more coordination and exchange more information before going ahead to edit the original article. The articles themselves did not differ between script groups, neither in text length nor in the number of newly added arguments. Regarding the learning outcomes and acquisition of the partner's arguments, the students showed some meaningful differences depending on their script. In the knowledge tests the DDR students scored slightly higher on average, but more impressively they were much more likely to incorporate more information and arguments from their learning partner's material, at least for the study's main topic about William Kidd's pirate status. The correlations of the NCC with the wiki metrics and learning outcome did not show any clear patterns, which is likely due to the small sample and thus a relatively high sampling variability. Overall, put cautiously, it seemed that the DDR script encouraged students who are high on the NCC scale to be more engaged in the knowledge construction process by writing slightly longer articles and adding more arguments to the text.

\section{Main study - Method}

\section{Participants and design}

The study had a two-group experimental design with the corresponding collaboration script texts and accompanying representations (BRD vs DDR) as the experimental manipulation. Ninety students in a course on Inferential Statistics for our university's program in Applied Cognitive and Media Science were invited to take part in the experiment and completed the pre-test (t1). Due to attrition, $N=69$ of them completed all stages of the experiment. Students were aged 18 to 27 years $(M=20.59, S D=2.02)$ and consisted of $56(81.16 \%)$ females and $23(18.84 \%)$ males. The two groups did not differ substantially from each other regarding prior knowledge, as reflected in the pre-test scores (cf. Table 5). After the pre-test, the study's main collaboration phase was conducted in a natural wiki setting with random group allocation. Two weeks after the pre-test, participants were asked to take part in a post-test about the study's wiki contents (t2).

Table 5. Descriptive statistics and analysis of pre-test scores.

\begin{tabular}{lccccccc}
\hline & & $M$ & $S D$ & $t(58.96)$ & $p$ & $d$ & $95 \%$ CI \\
\hline Pre-test scores & BRD & 13.39 & 1.71 & & & & \\
& DDR & 12.91 & 1.36 & 1.26 & .211 & 0.31 & {$[-0.17,0.78]$} \\
\hline
\end{tabular}

\section{Procedure and variables}

The basis for our wiki materials was created in an earlier study, conducted the previous semester by the same student cohort where students worked in small groups of two to four people (Mock, 2017). They created ten wiki pages and wrote nine articles about statistical topics; one topic was 
left with a blank article template. The resulting articles were used as the original articles in the current experiment.

The main task for students in our main study was to review and revise the previously created articles. To conduct our experiment with larger student groups, two DokuWiki instances served as experimental wikis in which we included either the BRD or the DDR script as detailed texts with added visual representations. Students were first led to a start page where they were provided with the detailed text instructions about their respective collaboration script procedures in a mandatory tutorial. As permanently visible reminders of the most relevant stages, graphical script representations appeared in the header of each wiki page. In addition, the scripts' main stages were also included as textual workflow representations in the wikis' navigation panes (cf. Figure 7). Students in both wiki groups had a period of two weeks for collaboratively working on the articles.

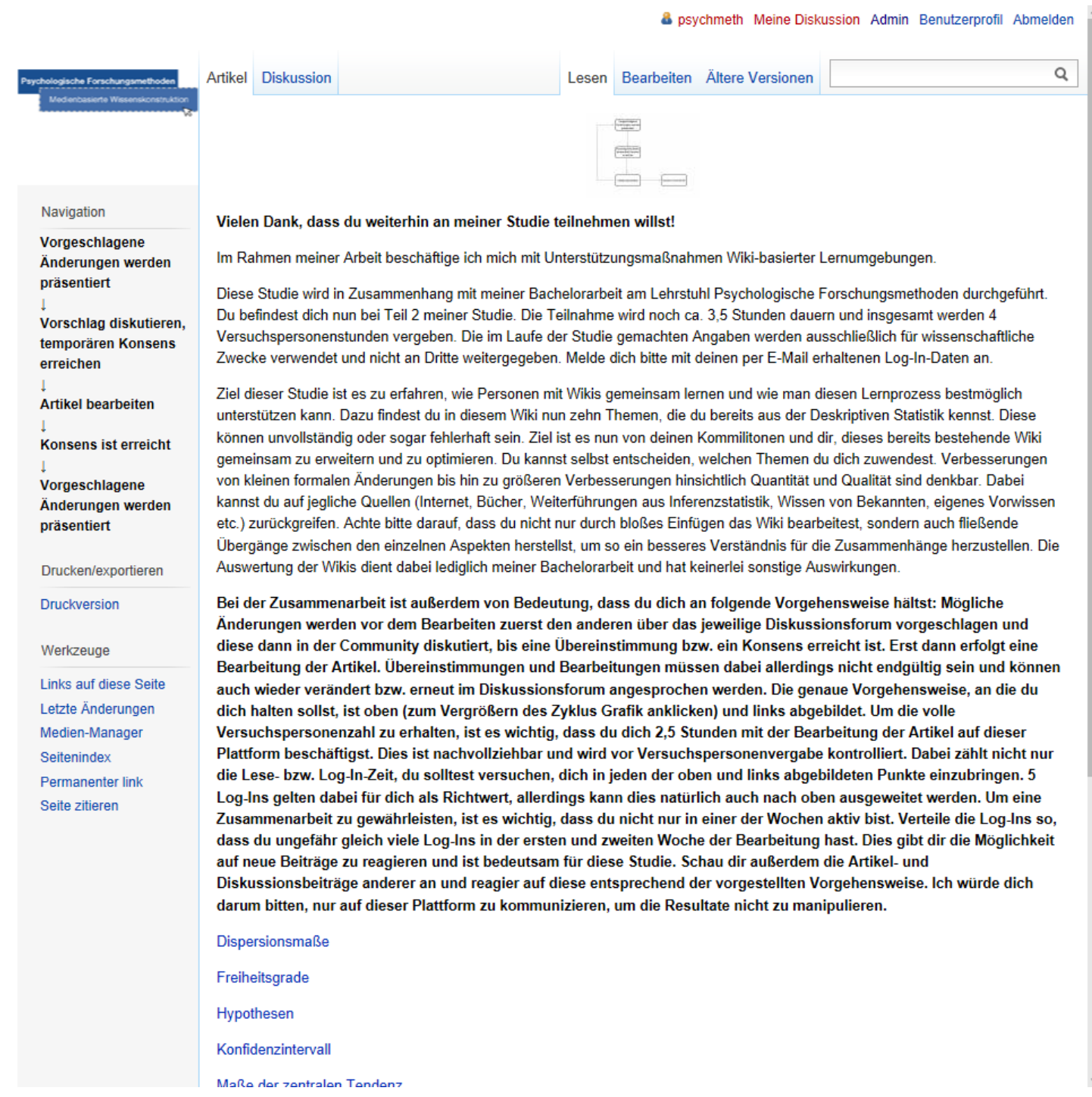

Figure 8. Wiki-based learning environment with collaboration script text and added representations in the main study. The bold printed text on the main page were the detailed script instructions. 
To measure the learning gains as our main dependent variable we conducted two knowledge tests. Prior to the wiki collaboration all participants received a 20-item knowledge test with five answer choices as the pre-test (e.g. "Which values are needed to calculate the confidence interval?"). After the collaborative writing phase participants answered another 20-item knowledge post-test that was structurally identical to the pre-test, also with five answer choices each (e.g. "Which conditions have to be satisfied to conduct a t-test?"). Each wiki topic was addressed by two questions in both tests. Each question had one to three correct answer options. We ensured that question difficulty, content areas, and the number of correct answer options per item were similar between the pre- and post-tests to create equivalent question sets. For both tests, the questions were generated using the original, unedited material in the wikis. The total number of points for both tests was set to the number of questions (20). Participants could get 0.2 points for both choosing correct answers and not choosing false answers. Additionally, we gathered wiki metrics, such as number of revisions per article, number of discussions per article, article word count and number of article errors. For further analyses, we also assessed individual variables as potential moderators, namely the NCC, metacognitive strategies, and intrinsic motivation. The questionnaire to assess metacognitive strategies was taken from the inventory for the acquisition of learning strategies in studying (Wild \& Schiefele, 1994). This is a 77-item questionnaire for the assessment of cognitive, metacognitive, and resource-related learning strategies. As this study focused on the metacognitive strategies, the inventory was reduced to the eleven relevant items measuring this factor (e.g., "I ask myself questions about the material to make sure that I have understood everything.") with answer options scaled from 1 ("very rare") to 5 ("very often"). To assess intrinsic motivation, the German short scale of intrinsic motivation (Wilde et al., 2009) was used, which is an adapted version of the Intrinsic Motivation Inventory (Deci \& Ryan, 2003). This scale has a four-dimensional factor structure and consists of the sub-scales Interest/Enjoyment (e.g., "The collaboration was enjoyable."), Perceived Competence (e.g., "I think I was pretty good in the collaboration."), Perceived Choice (e.g., "In the collaboration I could choose on my own how to handle it."), and Pressure/Tension (e.g., "While collaborating I was tense.") with three items in each subscale. Answers were given on a 5-point Likert scale from 1 = "strongly disagree" to $5=$ "strongly agree". ). Figure 8 shows the overall study procedure and highlights when the independent variable was manipulated, and dependent variables were measured.

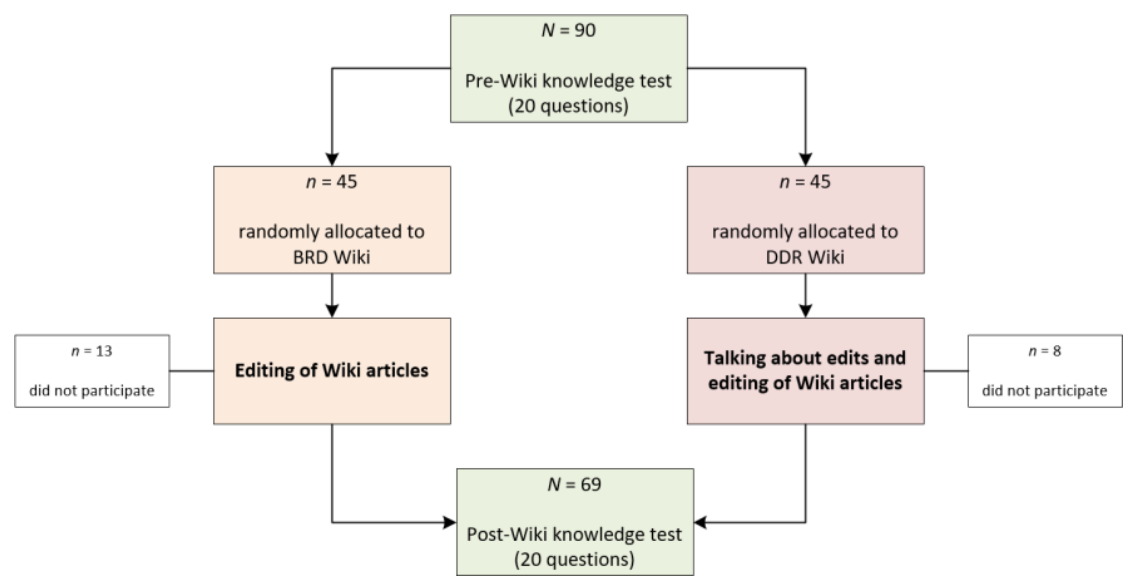

Figure 8. Overall study procedure of the main study. 


\section{Main study - Results and Discussion}

\section{Analytic procedure}

Due to the larger sample as compared to the pre-study, we could use more sophisticated statistical methods to analyse the data. In addition to the direct two-group comparisons, we further conducted moderation analyses of the conditional effects of the NCC, metacognitive strategies and intrinsic motivation on wiki contribution frequency and learning gains. The final sample size of $N$ $=69$ provides statistical sensitivity with a minimum power of .80 for multiple regression model effect sizes of Cohen's $f^{2}=.117$ which approximately translates to medium to large effects of $R^{2}$ $=.10$ (Cohen, 1988).

If regions of significance were found by the PROCESS macro for SPSS when applying the Johnson-Neyman technique, we visualised the conditional effect slope and its $95 \%$ upper and lower confidence bands. Otherwise simple slopes are presented for better visualisation purposes (Hayes, 2013). As a final analytic step, we explored potential links between collaboration scripts and learning outcomes after collaboration, mediated by wiki contributions frequency. For all moderator and mediator analyses, we applied bias-corrected and accelerated (BCa) bootstrapping with 10,000 random resamples that can produce reliable parameter estimates even for mediumsized samples of $N>50$ (Fritz \& MacKinnon, 2007).

\section{Direct group comparisons}

Wiki metrics. Regarding the wiki contributions, students in the DDR group participated much more frequently in talk page discussions and edited less to the wiki articles than students in the BRD group (cf. Table 6). These contribution metrics results from the wiki log data show that the scripts induced the intended collaborative knowledge construction behaviour for both groups. Students in both groups adhered to their respective collaboration scripts during the two-week long experimental collaboration phase, focusing either on high edit frequency (BRD) or the discussion and deliberation of content changes (DDR).

Table 6. Descriptive statistics and analyses of edit and discussion frequencies.

\begin{tabular}{lcrrrrrrr}
\hline \multirow{2}{*}{ Edits } & & \multicolumn{1}{c}{$M$} & \multicolumn{1}{c}{$S D$} & $t$ & $d f$ & $p$ & $d$ & $95 \%$ CI \\
& BRD & 12.47 & 10.35 & & & & & \\
& DDR & 7.43 & 9.34 & 2.11 & 63.09 & .019 & 0.51 & {$[0.03,0,99]$} \\
\hline \multirow{2}{*}{ Discussions } & BRD & 0.28 & 0.81 & & & & & \\
& DDR & 13.87 & 11.01 & 7.48 & 36.45 & $<.001$ & 1.68 & {$[1.12,2.23]$} \\
\hline
\end{tabular}

We also found that the BRD group added more words $(M d n=353.50)$ to the original articles than the DDR group $(M d n=105.00), U=87.00, p=.012, r=.58,95 \%$ CI $[.24, .80]$. A direct group comparison of the relative error rate per 100 words shows a major difference in favour of the DDR group ( $M d n=0.90$ for DDR, $M d n=1.75$ for BRD), $U=82.00, p=.007, r=.64,95 \% \mathrm{CI}$ $[.31, .83]$. A positive correlation with a moderate to large effect between article length and the 
relative number of errors per article supports the former test, $r_{s}(18)=.48, p=.017,95 \%$ CI $[.05$, .76] (cf. Figure 9). These results show that the exhaustiveness of an article does not necessarily reflect its quality and that shorter articles are potentially more precise and have fewer errors.

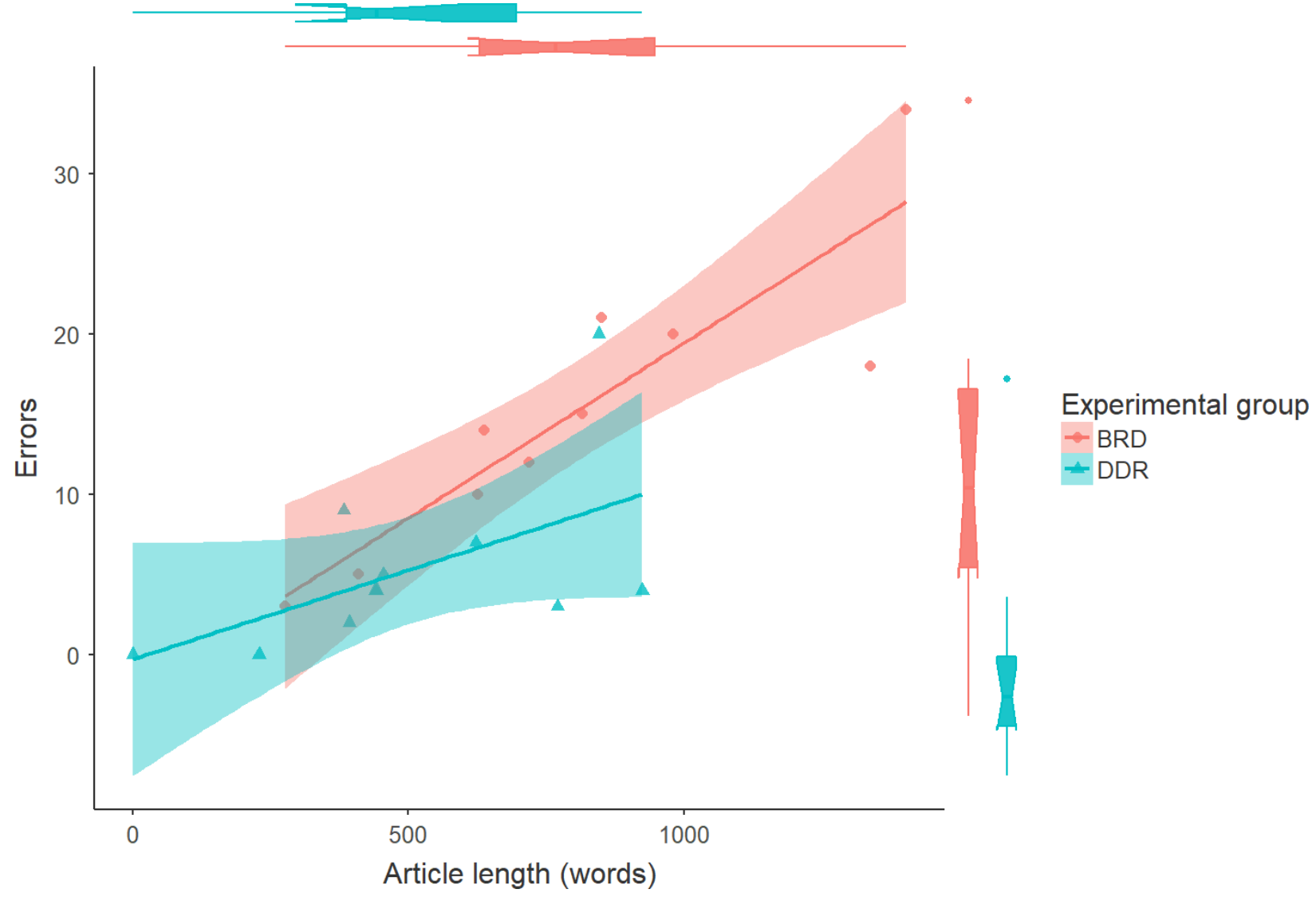

Figure 9. Scatterplot for the relationship between article length and number of errors made with regression slopes as outcomes per experimental group.

Learning outcomes. Students in the DDR group performed minimally better in terms of absolute gains from the knowledge pre-test to the post-test, but the magnitude of the scripting effect was negligibly small and the statistics for this test were estimated with fairly low precision. Beyond that, a paired samples $t$-Test clearly suggested that students in both groups showed a performance increase from the first knowledge test to the second knowledge test with a medium to large effect for the time of testing (cf. Table 7). Thus, students mostly benefitted from simply working with a wiki for the study period of two weeks. Their learning gains were not directly influenced by the collaboration script group they were assigned to. 
Table 7. Descriptive statistics and analyses of learning outcomes.

\begin{tabular}{|c|c|c|c|c|c|c|c|c|}
\hline & & $M$ & $S D$ & $t$ & $d f$ & $p$ & $d$ & $95 \% \mathrm{CI}$ \\
\hline Learning & BRD & 0.91 & 1.54 & & & & & \\
\hline gains & DDR & 1.04 & 1.43 & 0.35 & 63.94 & .364 & 0.08 & {$[-0.39,0.56]$} \\
\hline Test & Pre & 13.13 & 1.54 & & & & & \\
\hline scores & Post & 14.11 & 1.53 & 5.52 & 68 & $<.001$ & 0.66 & {$[0.40,0.92]$} \\
\hline
\end{tabular}

Conditional effects of influencing variables on contribution frequency

Next, we analysed the potential moderation effects of the additionally assessed variables. The overall model effect statistics for the three conditional effects that we investigated for (1) the NCC, (2) metacognitive strategies, and (3) intrinsic motivation on the contribution frequency are shown in Table 8.

Table 8. Conditional effect models of the influencing variables on contribution frequency.

\begin{tabular}{lrrrr}
\hline & $F(3,65)$ & $p$ & \multicolumn{1}{l}{$R^{2}$} & \multicolumn{1}{l}{$95 \%$ CI } \\
\hline Need for Cognitive Closure & 2.60 & .060 & .10 & {$[.00, .24]$} \\
Metacognitive strategies & 3.23 & .028 & .13 & {$[.00, .27]$} \\
Intrinsic motivation & 3.29 & .026 & .29 & {$[.00, .45]$} \\
\hline
\end{tabular}

Students with a high Need for Cognitive Closure contributed more to the wiki when they were in the DDR script group (Figure 10, left). For students with a low NCC the overall contribution frequency was not affected by the wiki script group they used. The DDR script encouraged those students, who would normally contribute less due to their disposition, to collaborate more. Students who had less pronounced metacognitive strategies contributed significantly more to a wiki when they were assigned to the DDR script, while those with more pronounced metacognitive strategies did not differ in their contribution frequency between groups (Figure 10, middle). The DDR script seems to encourage contributions from students who need more explicit guidance on what to do in a collaborative knowledge construction task. Students in the DDR script wiki contributed the most when their motivation was high (Figure 10, right). When motivation was low, the contribution frequency in the DDR script group showed a slightly reversed effect resulting in almost equally few contributions as in the BRD script wiki. Motivation seems to play a key role for participation in collaborative knowledge construction activities if the deployed script is more restrictive. 

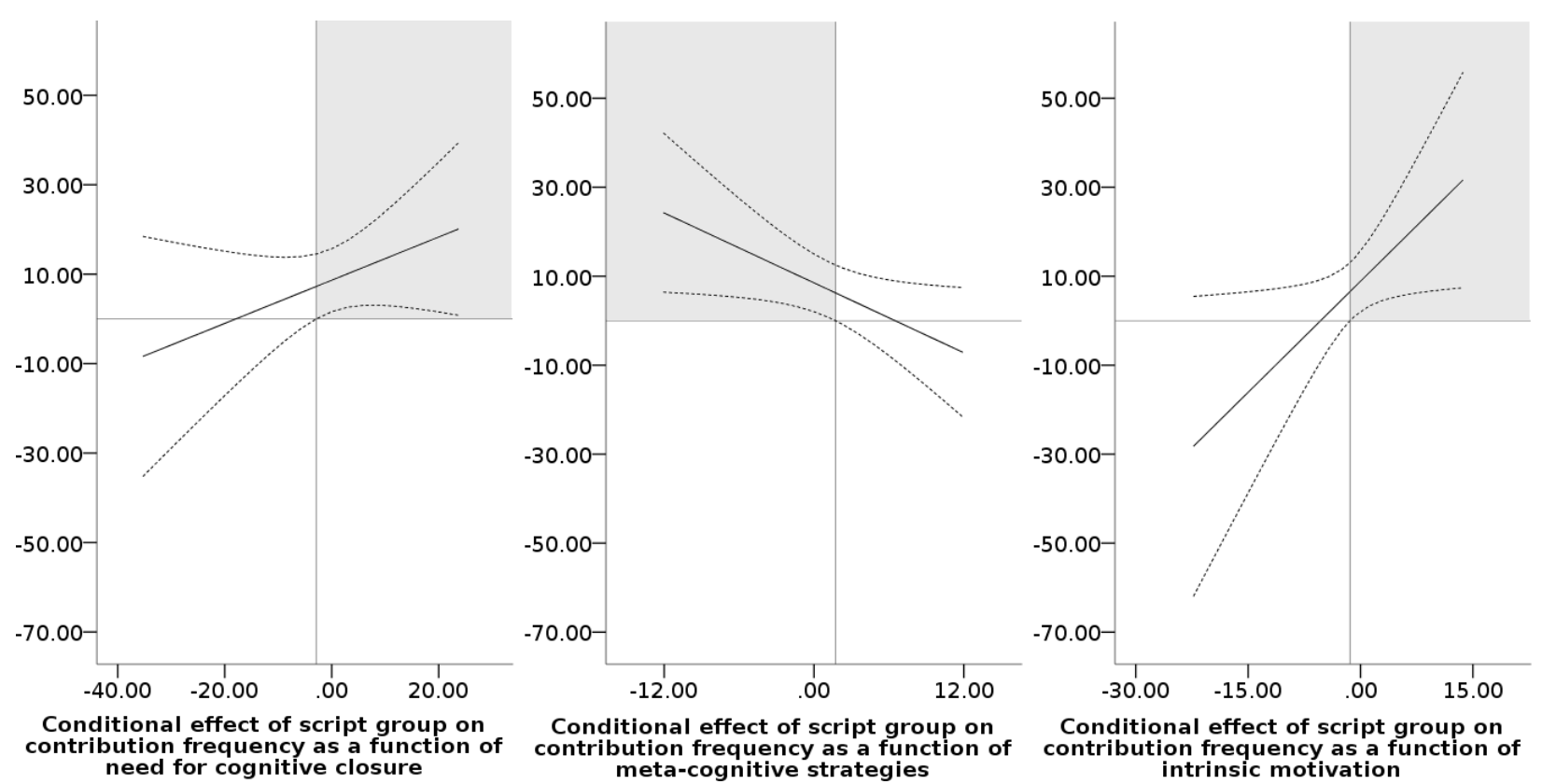

Figure 10. Conditional effects of script group on contributions as functions of: NCC (left), metacognitive strategies (middle), intrinsic motivation (right). Grey area $=$ Johnson-Neyman region of significance; Dashed lines $=95 \%$ upper and lower confidence bands.

\section{Conditional effects of influencing variables on learning}

For all analyses of the three influencing variables on learning gains from the pre- to the posttest, the Johnson-Neyman floodlight analysis did not find any regions of significance. The overall model effect statistics for the three conditional effects on the learning outcomes are shown in Table 9. Thus, for the sake of completeness we used simple slopes as visualisations of the minor differences, although estimated with low precision.

Table 9. Conditional effect models of the influencing variables on learning outcomes.

\begin{tabular}{lrrrr}
\hline & $F(3,65)$ & $p$ & \multicolumn{1}{l}{$R^{2}$} & \multicolumn{1}{l}{$95 \%$ CI } \\
\hline Need for Cognitive Closure & 0.87 & .460 & .04 & {$[.00, .13]$} \\
Metacognitive strategies & 0.61 & .610 & .03 & {$[.00, .10]$} \\
Intrinsic motivation & 0.10 & .960 & .01 & {$[.00, .03]$} \\
\hline
\end{tabular}

Students who were high on the closure scale had the larger gains in the BRD wiki compared to students who were low on the scale who performed slightly better in the DDR wiki. However, for both script groups and both extremes on the NCC scale the average gains in test scores were relatively small ranging from 0.6 to 1.3 more correct answers from pre- to post-test (Figure 11, left). Having low levels of metacognitive strategies does not discriminate much between students of either wiki script, with a marginal advantage for those in the DDR group. Conversely, students who are high on the metacognitive strategy spectrum performed slightly better when collaborating in the BRD wiki (Figure 11, middle). For students with elevated levels of intrinsic motivation it 
made virtually no difference to which wiki script group they were assigned, resulting in almost identical learning gains. Students who had low intrinsic motivation for collaborating with other students in the wiki performed marginally better when they were working in the less strictly structured BRD wiki (Figure 11, right).
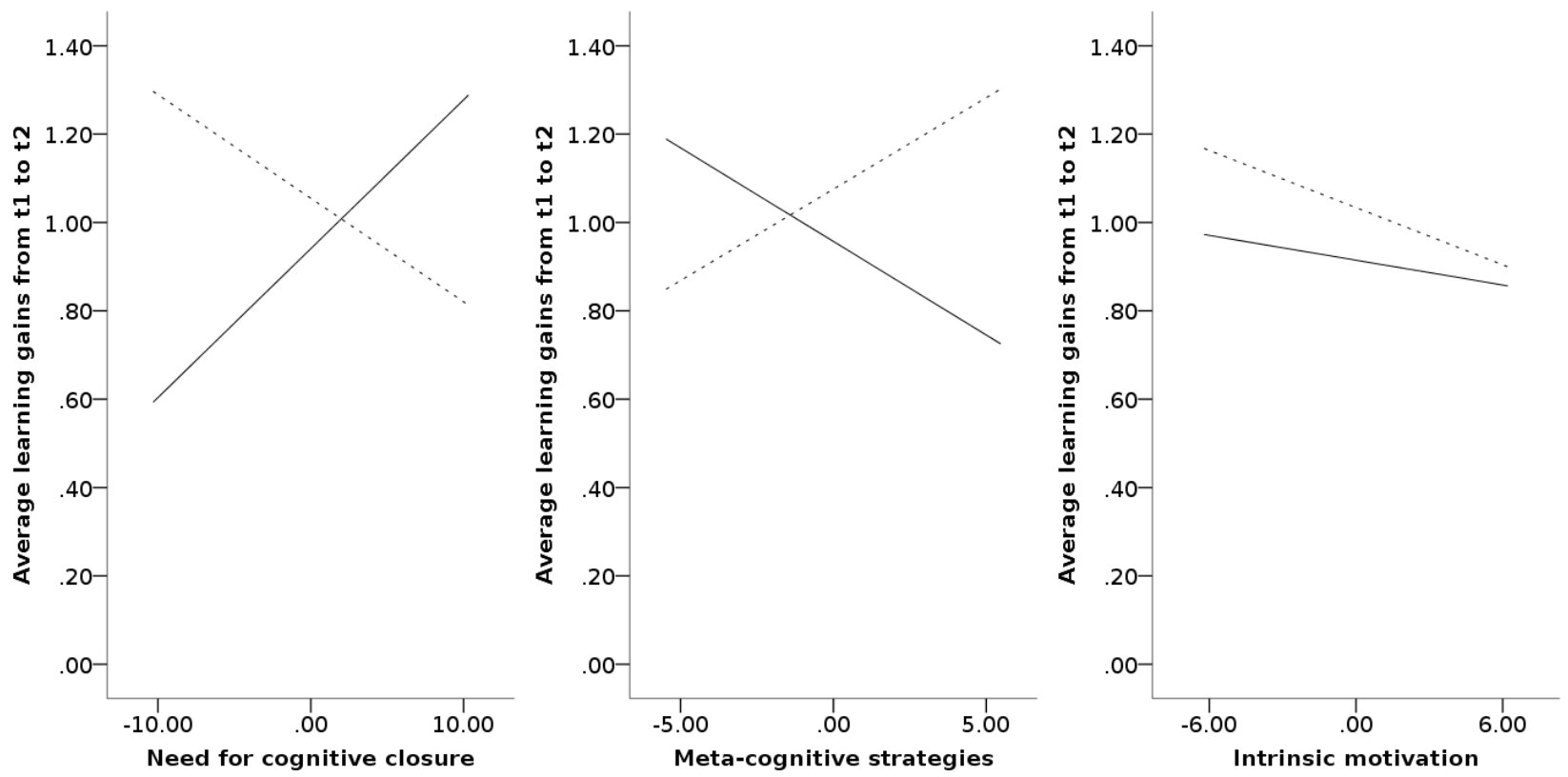

Figure 11. Simple slopes of script groups on learning gains conditional of influencing variables: NCC (left), metacognitive strategies (middle), intrinsic motivation (right). Dashed lines = BRD, solid lines $=$ DDR.

\section{Contribution frequency as mediator between script and learning}

A simple mediation analysis with OLS path analysis suggested that the provided collaboration scripts indirectly influenced the learning outcome at the post-test after collaboration ( $\mathrm{t} 2$ ) through the students' wiki contribution frequency (cf. Figure 12) Students in the DDR wiki made on average more contributions to the wiki than students in the BRD group, $a=8.55,95 \%$ CI [1.52, 15.57]. Thus, students who contributed more to the wiki were more likely to achieve a higher posttest score, $b=0.024,95 \%$ CI $[0.006,0.043]$. A bias-corrected bootstrap confidence interval for the indirect effect was entirely above zero, $a b=.21,95 \% \mathrm{CI}[.02, .52]$. The total effect model for the unmediated effect highlights that the data do not sufficiently support a direct effect of the collaboration script on learning outcomes in the post-test, $F(1,67)=0.89, p=.349, R^{2}=.01,95 \%$ CI $[.00, .12]$. 


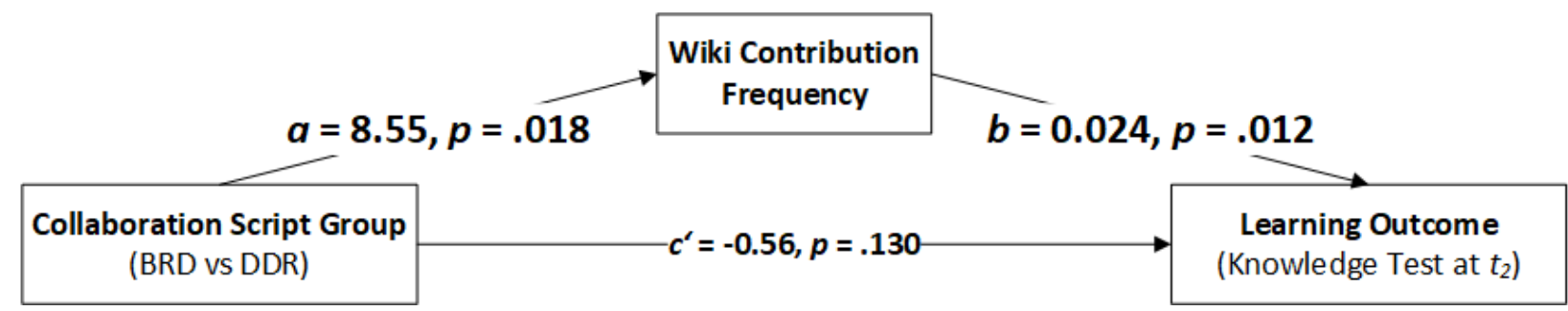

Figure 12. Effect of collaboration script on learning outcome mediated by the frequency of contributions to the wikis.

\section{Further results}

Regarding the attitudes towards collaboratively working with collaboration scripts and Wikis, we were interested in how helpful participants perceived our experimental Wikis. 67.57\% of participants in the DDR group found that working with a wiki was generally useful compared to $71.88 \%$ in the BRD group, $\chi^{2}(1, N=69)=0.15, p=.796$. In the DDR group $83.78 \%$ of students perceived their provided script for collaboration with Wikis as useful compared to $90.32 \%$ of students in the BRD group, $\chi^{2}(1, N=68)=0.63, p=.494$. In the DDR group $51.35 \%$ stated that they intend to use a wiki also in future works compared to $65.63 \%$ in the BRD group, $\chi^{2}(1, N=$ 69) $=1.44, p=.328$.

\section{Summary of the main study's key findings}

The central result of the main study is that students following different collaboration scripts in a real collaborative wiki environment show crucial differences in the resulting outcomes and underlying processes. Following the DDR script encouraged students to discuss substantial changes to articles before an edit was performed, while the BRD script group discussed virtually nothing and performed changes to the wiki whenever they felt the need. In most cases, students in the BRD wiki did not advance to the script's other steps of reverting and discussion. The script's aim is to promote many edits to an article; if no objections are communicated via revisions or discussions, we can assume that the community reached an implicit consensus about the performed edits. In contrast, in the DDR wiki we could see many discussions between several students about the subject matter's subtopics. Accordingly, we can assume that the whole suggested script was followed by most participants, since we saw the entire process of proposing an article edit in a discussion, followed by a deliberation process to reach consensus that finally resulted in a corresponding article edit. On the one hand, students produced longer articles in the BRD wiki, but on the other hand we found fewer errors in the DDR wiki articles. The greatest learning success at the post-test was most likely to be achieved when involvement in the wiki community was high, which was especially the case for students in the DDR script group. In extension to the pre-study, we explored further influencing variables thought to be related to learning and knowledge construction, namely the NCC, metacognitive strategies, and intrinsic motivation. We showed that it is relevant to consider individual differences in these constructs when designing instructional aids for collaborative learning environments. 


\section{General Discussion and Conclusions}

Providing learners in technology-enhanced environments with explicit guidance on how to continue with collaborative tasks can be highly relevant for more successful individual learning outcomes and collaborative knowledge construction artefacts. For the start of new wiki articles or similar collaboratively created user-generated content, following an open script as proposed with Wikipedia's BRD can be useful. This script proposal encompasses the main stages of performing an article edit without any discussion (Be Bold), waiting to see if an edit will be reverted by another community member (Revert), and only take the edit as a topic to the discussion page if it gets reverted multiple times (Discuss). In contrast to that approach, when there is already a wiki knowledge base which can be built upon, it can be more useful to follow a script like DDR. That approach explicitly expects learners to coordinate and seek consensus before changes to the system are incorporated. Discussions are promoted to present any planned edits (Discuss), finding a consensus with the community (Deliberate), and finally editing the article according to the consensus (Revise). Therefore, we have examined in detail how students work with either script in dyads and in larger groups. We analysed differences in measurable learning outcomes and resulting artefacts that students produced in the experimental wiki environments. It is important to note that we focused in this article solely on quantitative measures of outcome and process variables. There were no deeper content analyses to assess the quality of individual or group contributions as we have preliminary worked with a random sample (Heimbuch \& Bodemer, 2016). Quality of wiki contributions was indirectly derived with wiki metrics such as article and discussion lengths as potential indicators for quality as well as the number of errors we identified relative to the article lengths.

In the small-scale pre-study with dyads, we first gathered valuable insights and evidence about how learners adopt distinct types of collaboration scripts designed for wikis. Moreover, we examined how this affects their learning outcomes and knowledge construction in a wiki-like environment. Although the sample was quite small for reliable statistical inferences, we could extract some valuable information from the learner's answers to our open-ended questions and some descriptive information. This information motivated us to further explore potentials of these two different script approaches. For the most part, both scripts worked as intended. Students in the wiki environment with the DDR used the chat much more often for coordinating and discussing what content to include into the main article text. We could see that when students followed our suggested DDR script they were much more likely to incorporate their learning partner's other information into more complex and nuanced answers. Although the number of well-integrated replies decreased over time, students who previously collaborated with the DDR script were still more likely to give more nuanced answers than their BRD counterparts. Thus, collaboration with the DDR script caused students to add their own and the learning partner's arguments to reach more balanced articles.

For the main study, we built upon the findings of the pre-study and set up two real wiki instances for larger student groups as a supplement to a statistics lecture. Both collaboration script proposals worked well on their intended modes of operation. Students in the BRD wiki produced many more edits directly to the article than those who were in the DDR group. The main task in the BRD script is about editing an article and if no community member has any objections, an implicit consensus 
is reached and no further script execution is needed. In the DDR wiki students discussed most of their intended changes, while in the BRD group there were virtually no discussions during the experiment's observation period of two weeks. Students in the DDR wiki executed all stages of the entire script proposal by starting discussions, taking part in consensus finding and performing article edits as the last prompted step. The DDR script encouraged students to discuss on a level that is usually not present in educational wikis and more likely to be found in threaded online forums (Biasutti, 2017). We wish to highlight the students' adoption of the DDR script steps and the resulting increased knowledge exchange about the subject matter in this group. In contrast to the pre-study, the main study's set-up and subject matter made the occurrence of controversies less likely, making it more difficult to see learners' incorporation of complex and nuanced replies. Nevertheless, we could find some major differences. The resulting articles of the DDR wiki students were shorter, but they were more concise and had fewer errors. In preliminary content analyses of a random sample of articles, we found that the articles produced in the DDR wiki were of higher overall quality (Heimbuch \& Bodemer, 2016). Furthermore, our analyses of the influencing variables suggest that our findings are important to consider from an applied perspective. Other researchers of collaborative knowledge construction environments concluded that students can benefit from reading, connecting, and questioning ideas in an online environment (So, Seah, \& Toh-Heng, 2010).

Based on our findings, we think that it is also relevant to consider inter-individual differences when designing and incorporating guidance measures into computer-supported collaborative learning environments. Considerations of cognitive constructs, such as those presented, can influence how students make use an online environment and what level of support might help them. In both experiments, we investigated effects of the individual Need for Cognitive Closure. The results might seem ambiguous at first sight, partially because although the construct is regarded as a relatively stable disposition, it has also state component that can be influenced by time pressure (Webster \& Kruglanski, 1994). The pre-study in the lab had much stricter time limits of 45 minutes for the collaboration phase, while in the main study students had two weeks for collaboration with the wikis. As such, an individual with a high Need for Cognitive Closure is likely to act differently under time pressure. For example, a high degree of the NCC leads to conflict avoidance behaviour and the use of heuristics (Dreu et al., 1999), while a low degree of NCC leads to the use of multiple information (Choi, Koo, Choi, \& Auh, 2008). It was therefore assumed in the hypotheses that this also leads to differences in wiki contribution behaviour and learning outcomes. This could only be confirmed statistically for the contribution frequency. After performing a simple slopes analysis for the learning gains, however, there was an effect that followed the expected direction at least descriptively. Accordingly, students of the DDR group showed slightly higher learning gains if their NCC was low, while high NCC participants benefitted more from collaborating with the BRD script. This can be attributed to a high dispositional NCC which is related to a reduction in internal hypothesis formation (Kruglanski \& Mayseless, 1987; Kruglanski \& Webster, 1996). Since the focus of the BRD script was more on increasing the edit frequency and article length, a special need for other perspectives and arguments, as it would be the case with a low NCC, would have been rather hindering. Decisions are thus based more on heuristics (De Dreu et al., 1999), while people with a low NCC use more information (Schlink, 2009). The latter was explicitly demanded in the DDR script wiki because 
before an article edit was performed, a consensus had to be reached. Thus an adoption of arguments or evidence by others was indispensable for new acquisition of knowledge. These findings should be used as a basis and attempts should be made to conduct replications. Regarding the other two constructs we assessed in the main study, metacognitive strategies and intrinsic motivation, we found that students in the more restrictive DDR wiki participated more than the average when they had few metacognitive strategies and were highly motivated. With high levels of metacognitive strategies, students do not necessarily need very explicit rules for effective collaboration, because they have already developed skills to easily adapt to specific requirements (Berthold et al., 2007; Kuhn, 2000). Finally, more intrinsic motivation can be needed in more restrictive collaborative environments such as the DDR wiki, since the individual's autonomy of what to do is constrained by the suggested workflow. The idea of perceived autonomy is more in line with the concept of Wikipedia's BRD script which is less coercive and designed to incentivise high participation rates and many article edits (Nov, 2007; Zhang \& Zhu, 2006).

In conjunction, both studies suggest that when students collaboratively create user-generated content in wikis and systems alike, it is important to define the aims of collaboration and the whole setup. If the major goal is to gather as much information as possible in a brief period and to fill up an empty knowledge base, open and less coercive guidance could be more suitable to achieve this, e.g., the BRD approach. But if there is an already existing and established stock of knowledge to be improved or revised, it might be more fruitful to guide in a more restricted manner and to encourage discussions that are otherwise found in online forums rather than wikis. Moreover, a more coercive script can induce more meaningful discussions and exchanges of arguments about contradictory evidence. Future studies should investigate how scalable collaboration scripts function, such as our DDR proposal, as well as if a critical mass of users can efficiently make use of such scripts.

\section{References}

Arazy, O., Morgan, W., \& Patterson, R. (2006). Wisdom of the Crowds: Decentralized Knowledge Construction in Wikipedia (SSRN Scholarly Paper No. ID 1025624). Rochester, NY: Social Science Research Network.

Bartelsen, J., \& Brauer, J. (2010). Kooperatives Lernen mit einem Wiki. Elmshorn: Nordakademie.

Bell, N., Grossen, M., \& Perret-Clermont, A.-N. (1985). Sociocognitive conflict and intellectual growth. New Directions for Child and Adolescent Development, 1985(29), 41-54. https://doi.org/10.1002/cd.23219852905

Berthold, K., Nückles, M., \& Renkl, A. (2007). Do learning protocols support learning strategies and outcomes? The role of cognitive and metacognitive prompts. Learning and Instruction, 17(5), 564-577. https://doi.org/10.1016/j.learninstruc.2007.09.007

Biasutti, M. (2017). A comparative analysis of forums and wikis as tools for online collaborative learning. Computers \& Education, 111, 158-171. https://doi.org/10.1016/j.compedu.2017.04.006

Biasutti, M., \& EL-Deghaidy, H. (2012). Using Wiki in teacher education: Impact on knowledge management processes and student satisfaction. Computers \& Education, 59(3), 861-872. https://doi.org/10.1016/j.compedu.2012.04.009 
Blumenstock, J. E. (2008). Size Matters: Word Count As a Measure of Quality on Wikipedia. In Proceedings of the 17th International Conference on World Wide Web (pp. 1095-1096). New York, NY, USA: ACM. https://doi.org/10.1145/1367497.1367673

Bromme, R., Hesse, F. W., \& Spada, H. (Eds.). (2005). Barriers and biases in computer-mediated knowledge communication - and how they may be overcome (Vol. 5). New York, NY: Springer.

Chen, Y.-H., Jang, S.-J., \& Chen, P.-J. (2015). Using wikis and collaborative learning for science teachers' professional development. Journal of Computer Assisted Learning, 31(4), 330344. https://doi.org/10.1111/jcal.12095

Choi, J. A., Koo, M., Choi, I., \& Auh, S. (2008). Need for cognitive closure and information search strategy. Psychology and Marketing, 25(11), 1027-1042. https://doi.org/10.1002/mar.20253

Cohen, J. (1988). Statistical Power Analysis for the Behavioral Sciences. Routledge.

Cole, M. (2009). Using Wiki technology to support student engagement: Lessons from the trenches. Computers \& Education, 52(1), 141-146. https://doi.org/10.1016/j.compedu.2008.07.003

Cress, U., \& Kimmerle, J. (2008). A systemic and cognitive view on collaborative knowledge building with wikis. International Journal of Computer-Supported Collaborative Learning, 3(2), 105. https://doi.org/10.1007/s11412-007-9035-z

Cress, U., \& Kimmerle, J. (2017). The Interrelations of Individual Learning and Collective Knowledge Construction: A Cognitive-Systemic Framework. In S. Schwan \& U. Cress (Eds.), The Psychology of Digital Learning (pp. 123-145). Cham: Springer International Publishing. https://doi.org/10.1007/978-3-319-49077-9_7

De Grada, E., Kruglanski, A. W., Mannetti, L., \& Pierro, A. (1999). Motivated Cognition and Group Interaction: Need for Closure Affects the Contents and Processes of Collective Negotiations. Journal of Experimental Social Psychology, 35(4), 346-365. https://doi.org/10.1006/jesp.1999.1376

Deci, E. L., \& Ryan, R. M. (1985). Intrinsic Motivation and Self-Determination in Human Behavior. Springer.

Deci, E. L., \& Ryan, R. M. (1992). The initiation and regulation of intrinsically motivated learning and achievement. In Achievement and motivation: A social-developmental perspective (pp. 9-36).

Deci, E. L., \& Ryan, R. M. (2003). Intrinsic motivation inventory. Self-Determination Theory, 267.

Dillenbourg, P. (2002). Over-scripting CSCL: The risks of blending collaborative learning with instructional design. In P. A. Kirschner (Ed.), Three worlds of CSCL. Can we support CSCL? (pp. 61-91). Heerlen, Open Universiteit Nederland.

Dillenbourg, P., Järvelä, S., \& Fischer, F. (2009). The Evolution of Research on ComputerSupported Collaborative Learning. In N. Balacheff, S. Ludvigsen, T. de Jong, A. Lazonder, \& S. Barnes (Eds.), Technology-Enhanced Learning (pp. 3-19). Dordrecht: Springer Netherlands. https://doi.org/10.1007/978-1-4020-9827-7_1

Dreu, C. K. W. de, Koole, S. L., \& Oldersma, F. L. (1999). On the Seizing and Freezing of Negotiator Inferences: Need for Cognitive Closure Moderates the Use of Heuristics in 
Negotiation. Personality and Social Psychology Bulletin, 25(3), 348-362. https://doi.org/10.1177/0146167299025003007

Efklides, A. (2006). Metacognition and affect: What can metacognitive experiences tell us about the learning process? Educational Research Review, 1(1), 3-14. https://doi.org/10.1016/j.edurev.2005.11.001

Efklides, A. (2008). Metacognition - Defining Its facets and levels of functioning in relation to self-regulation and co-regulation. European Psychologist, 13(4), 277-287. https://doi.org/10.1027/1016-9040.13.4.277

Flavell, J. H. (1974). The development of inferences about others. In Understanding other persons (pp. xv, 266). Oxford, England: Rowman and Littlefield.

Flavell, J. H. (1979). Metacognition and cognitive monitoring: A new area of cognitivedevelopmental inquiry. American Psychologist, 34(10), 906-911. https://doi.org/10.1037/0003-066X.34.10.906

Franklin, T., \& Harmelen, M. van. (2007). Web 2.0 for Learning and Teaching in Higher Education. London: The Observatory of Borderless Higher Education.

Fritz, M. S., \& MacKinnon, D. P. (2007). Required Sample Size to Detect the Mediated Effect. Psychological Science, 18(3), 233-239. https://doi.org/10.1111/j.1467-9280.2007.01882.x

Hayes, A. F. (2013). Introduction to Mediation, Moderation, and Conditional Process Analysis: A Regression-Based Approach. Guilford Press.

Heimbuch, S., \& Bodemer, D. (2015). Need for cognitive closure as determinant for guidance in Wiki-based learning. In 23rd International Conference on Computers in Education (ICCE 2015) (pp. 10-12). Asia-Pacific Society for Computers in Education.

Heimbuch, S., \& Bodemer, D. (2016). Effects of Implicit Guidance on Contribution Quality in a Wiki-based learning environment. In 12th International Conference of the Learning Sciences (ICLS 2016) (Vol. 2, pp. 906-909). International Society of the Learning Sciences.

Hox, J. J., Moerbeek, M., \& Schoot, R. van de. (2010). Multilevel Analysis: Techniques and Applications, Second Edition. Routledge.

Huang, F. L. (2016). Alternatives to Multilevel Modeling for the Analysis of Clustered Data. The Journal of Experimental Education, 84(1), 175-196. https://doi.org/10.1080/00220973.2014.952397

Isaacs, E. A., \& Clark, H. H. (1987). References in Conversation Between Experts and Novices. Journal of Experimental Psychology, 116(1), 26-37. https://doi.org/10.1037/00963445.116.1.26

Järvelä, S., Volet, S., \& Hana Järvenoja. (2010). Research on Motivation in Collaborative Learning: Moving Beyond the Cognitive-Situative Divide and Combining Individual and Social Processes. Educational Psychologist, 45(1), 15-27. https://doi.org/10.1080/00461520903433539

Johnson, D. W., \& Johnson, R. (1985). Classroom conflict: Controversy versus debate in learning groups. American Educational Research Journal, 22(2), 237-256. https://doi.org/10.3102/00028312022002237 
Johnson, D. W., Johnson, R. T., \& Smith, K. A. (2000). Constructive controversy: The educative power of intellectual conflict. Change: The Magazine of Higher Learning, 32(1), 28-37. https://doi.org/10.1080/00091380009602706

Kenny, D. A. (1995). The effect of nonindependence on significance testing in dyadic research. Personal Relationships, 2(1), 67-75. https://doi.org/10.1111/j.1475-6811.1995.tb00078.x

Kirschner, P. A., Sweller, J., \& Clark, R. E. (2006). Why minimal guidance during instruction does not work: An analysis of the failure of constructivist, discovery, problem-based, experiential, and inquiry-based teaching. Educational Psychologist, 41(2), 75-86. https://doi.org/10.1207/s15326985ep4102_1

Kollar, I., Fischer, F., \& Hesse, F. W. (2006). Collaboration scripts - A conceptual analysis. Educational Psychology Review, 18(2), 159-185. https://doi.org/10.1007/s10648-0069007-2

Kruglanski, A. W., \& Mayseless, O. (1987). Motivational effects in the social comparison of opinions. Journal of Personality and Social Psychology, 53(5), 834-842. https://doi.org/10.1037/0022-3514.53.5.834

Kruglanski, A. W., \& Webster, D. M. (1996). Motivated closing of the mind: 'Seizing' and 'freezing.' Psychological Review, 103(2), 263-283. https://doi.org/10.1037/0033295X.103.2.263

Kuhn, D. (2000). Metacognitive Development. Current Directions in Psychological Science, 9(5), 178-181. https://doi.org/10.1111/1467-8721.00088

Leppink, J. (2010). Adjusting cognitive load to the student's level of expertise for increasing motivation to learn. In C. Reading (Ed.), Data and context in statistics education: Towards an evidence-based society (p. 4). Ljubljana, Slovenia.

Leppink, J., Gog, T., Paas, F., \& Sweller, J. (2015). Cognitive load theory: researching and planning teaching to maximise learning. In Researching Medical Education (pp. 207-218). Wiley-Blackwell. https://doi.org/10.1002/9781118838983.ch18

Lih. (2004). Wikipedia as Participatory Jo urnalism: Reliable Sources? Metrics for evaluating collabor ative media as a news resource. Presented at the 5th International Symposium on Online Journalism, University of Texas at Austin.

Mock, A. (2017). Open (ed) Classroom-Who cares? MedienPädagogik: Zeitschrift Für Theorie Und Praxis Der Medienbildung, 28, 57-65.

Nakamura, J., \& Csikszentmihalyi, M. (2014). The Concept of Flow. In Flow and the Foundations of Positive Psychology (pp. 239-263). Springer Netherlands. https://doi.org/10.1007/97894-017-9088-8_16

Neuenhaus, Nora. (2011). Metakognition und Leistung: Eine Längsschnittuntersuchung in den Bereichen Lesen und Englisch bei Schülerinnen und Schülern der fünften und sechsten Jahrgangsstufe. Otto - Friedrich - Universität Bamberg, Bamberg.

Notari, M., Reynolds, R. B., Chu, S., \& Honegger, B. D. (2016). The wiki way of learning: creating learning experiences using collaborative web pages.

Nov, O. (2007). What motivates Wikipedians? Communications of the ACM, 50(11), 60-64. https://doi.org/10.1145/1297797.1297798 
Papadopoulos, P. M., Demetriadis, S. N., \& Weinberger, A. (2013). 'Make it explicit!': Improving collaboration through increase of script coercion. Journal of Computer Assisted Learning, 29(4), 383-398. https://doi.org/10.1111/jcal.12014

Piaget, J. (1977). Problems of equilibration. In M. H. Appel \& L. S. Goldberg (Eds.), Topics in Cognitive Development (pp. 3-13). Springer US.

Posner, I. R., \& Baecker, R. M. (1992). How people write together. In Proceedings of the TwentyFifth Hawaii International Conference on System Sciences, 1992 (Vol. IV, pp. 127-138). https://doi.org/10.1109/HICSS.1992.183420

Richardson, W. (2010). Blogs, Wikis, Podcasts, and Other Powerful Web Tools for Classrooms. Corwin Press.

Rienties, B., Tempelaar, D., Van den Bossche, P., Gijselaers, W., \& Segers, M. (2009). The role of academic motivation in Computer-Supported Collaborative Learning. Computers in Human Behavior, 25(6), 1195-1206. https://doi.org/10.1016/j.chb.2009.05.012

Ruxton, G. D. (2006). The unequal variance t-test is an underused alternative to Student's t-test and the Mann-Whitney $\mathrm{U}$ test. Behavioral Ecology, 17(4), 688-690. https://doi.org/10.1093/beheco/ark016

Scardamalia, M., \& Bereiter, C. (1994). Computer support for knowledge-building communities. Journal of the Learning Sciences, 3(3), 265-283. https://doi.org/10.1207/s15327809jls0303_3

Schlink, S, \& Walther, E. (2007). Kurz und gut: Eine deutsche Kurzskala zur Erfassung des Bedürfnisses nach kognitiver Geschlossenheit. Zeitschrift Für Sozialpsychologie, 38(3), 153-161. https://doi.org/10.1024/0044-3514.38.3.153

Schlink, Susanne. (2009). Persönlichkeit entscheidet: Der Einfluss des Bedürfnisses nach kognitiver Geschlossenheit auf Entscheidungen unter Unsicherheit. Universität Trier.

Snijders, T. A. B., \& Bosker, R. J. (2011). Multilevel Analysis: An Introduction to Basic and Advanced Multilevel Modeling. SAGE.

So, H.-J., Seah, L. H., \& Toh-Heng, H. L. (2010). Designing collaborative knowledge building environments accessible to all learners: Impacts and design challenges. Computers \& Education, 54(2), 479-490. https://doi.org/10.1016/j.compedu.2009.08.031

Steiger, J. H. (2004). Beyond the F Test: Effect Size Confidence Intervals and Tests of Close Fit in the Analysis of Variance and Contrast Analysis. Psychological Methods, 9(2), 164-182. https://doi.org/10.1037/1082-989X.9.2.164

Stvilia et al. (2005). Information quality discussions in Wikipedia. In Proceedings of the 2005 International Conference on Knowledge Management (pp. 101-113).

Veenman, M. V. J., Van Hout-Wolters, B. H. A. M., \& Afflerbach, P. (2006). Metacognition and learning: Conceptual and methodological considerations. Metacognition and Learning, 1(1), 3-14. https://doi.org/10.1007/s11409-006-6893-0

Viegas, F., Wattenberg, M., Kriss, J., \& Ham, F. (2007). Talk Before You Type: Coordination in Wikipedia (pp. 78-78). IEEE. https://doi.org/10.1109/HICSS.2007.511

Vygotsky, L. (1986). Thought and Language - Revised Edition. The MIT Press.

Webster, D. M., \& Kruglanski, A. W. (1994). Individual differences in need for cognitive closure. Journal of Personality and Social Psychology, 67(6), 1049-1062. https://doi.org/10.1037/0022-3514.67.6.1049 
Weinberger, A., Stegmann, K., Fischer, F., \& Mandl, H. (2007). Scripting argumentative knowledge construction in computer-supported learning environments. In F. Fischer, I. Kollar, H. Mandl, \& J. M. Haake (Eds.), Scripting computer-supported collaborative learning (pp. 191-211). New York, NY: Springer.

Wichmann, A., \& Rummel, N. (2013). Improving revision in wiki-based writing: Coordination pays off. Computers \& Education, 62, 262-270. https://doi.org/10.1016/j.compedu.2012.10.017

Wikipedia:BRD. (2017, May 15). In Wikipedia. Retrieved from https://en.wikipedia.org/w/index.php?title=Wikipedia:BOLD,_revert,_discuss_cycle\&old id $=780453667$

Wild, K.-P., \& Schiefele, U. (1994). Lernstrategien im Studium: Ergebnisse zur Faktorenstruktur und Reliabilität eines neuen Fragebogens. [Learning strategies of university students: Factor structure and reliability of a new questionnaire.]. Zeitschrift Für Differentielle Und Diagnostische Psychologie, 15(4), 185-200.

Wilde et al. (2009). Überprüfung einer Kurzskala intrinsischer Motivation (KIM). Zeitschrift Für Didaktik Der Naturwissenschaften, (15/2009), 31-45.

Wilkinson, D. M., \& Huberman, B. A. (2007). Cooperation and quality in Wikipedia. In Proceedings of the 2007 International Symposium on Wikis (pp. 157-164). New York, NY: ACM. https://doi.org/10.1145/1296951.1296968

Zhang, X., \& Zhu, F. (2006). Intrinsic motivation of open content contributors: The case of Wikipedia. Presented at the Workshop on Information Systems and Economics (WISE), Chicago, IL.

Zheng, B., Niiya, M., \& Warschauer, M. (2015). Wikis and collaborative learning in higher education. Technology, Pedagogy and Education, 24(3), 357-374. https://doi.org/10.1080/1475939X.2014.948041

Zimmerman, B. J. (2002). Becoming a Self-Regulated Learner: An Overview. Theory Into Practice, 41(2), 64-70. https://doi.org/10.1207/s15430421tip4102_2 